\title{
ANALYTICAL METHODS FOR THE QUANTITATION OF AMLODIPINE BESYLATE AND ATORVASTATIN CALCIUM IN PHARMACEUTICAL DOSAGE FORM AND BIOLOGICAL FLUIDS
}

\author{
S. K. MANIRUL HAQUE*, MURAD ALSAWALHA
}

Department of Chemical and Process Engineering Technology, Jubail Industrial College, P. O. Box No. 10099, Zip Code-31961, Jubail Industrial City, Saudi Arabia

Email: Haque_m@jic.edu.sa

Received: 16 Feb 2019, Revised and Accepted: 28 Mar 2018

\section{ABSTRACT}

Amlodipine is the best-prescribed medication for cardiovascular disease major risk factor for hypertension and atorvastatin well known for diabetic. First discussed low cost ultraviolet-visible technique for the determination and quantitation of drugs in pharmaceuticals and biological fluids. Chromatographic techniques have an application with respect to trace analysis. Different types of chromatography such as high-performance liquid chromatography, high performance thin layer chromatography have most frequent applications in the field of pharmaceutical as well as biomedical analyses. Chromatography combined with mass spectrophotometry has the ability to collect molecular ion, followed to prepare a spectrum to assess molecular weight as well as structure. High-performance liquid chromatography coupled with mass spectrophotometry is a reliable and dynamic technique for the analysis of small and large drugs molecule. The advantages and disadvantages of all techniques are compared with each other with respect to sensitivity, reproducibility and other important parameters. The investigation also focused for the quantitation on both drugs in pharmaceutical preparations and plasma samples with the help of all available analytical techniques.

Keywords: Drugs, Amlodipine, Atorvastatin, HPLC, UPLC, TLC, HPTLC, CE, LCMS, UP-LCMS

(C) 2019 The Authors. Published by Innovare Academic Sciences Pvt Ltd. This is an open access article under the CC BY license (http://creativecommons.org/licenses/by/4.0/) DOI: http://dx.doi.org/10.22159/ijap.2019v11i3.32566

\section{INTRODUCTION}

Amlodipine besylate (fig. 1a) is scientifically known as (RS)-3-ethyl5-methyl-2-(2-aminoethoxymethyl)-4-(2-chlorophenyl)-1,4-dihydro -6-methyl-3,5-pyridinedicarboxylate benzene sulfonate. It was first introduced and prescribed for coronary artery disease. It was also helpful for angina and peripheral artery disease [1]. Now days mostly targeted for the patient having hypertension. The European Society of Cardiology was conducted survey until the year 2000 and their report based on statistical analysis showed nine hundred<smiles>CCOC(=O)C1=C(COCCN)NC(C)=C(C(=O)OC)C1c1ccccc1Cl</smiles>

(a) seventy-two million people were in this category. The number will increase with time and expected by the year 2025, approximately 1.56 billion [2]. This drug is under the umbrella of calcium channel blocker. The mechanism of such blockers to control the transportation of calcium to coronary (mainly smooth muscle) and arteries, that reflects on muscles became relaxes, reduces peripheral resistance and ultimately lowering the blood pressure [3]. Atorvastatin (fig. 1b) is chemically known as $(\beta \mathrm{R}, \quad \delta \mathrm{R})-2$-(4-fluorophenyl)- $\beta, \delta$-dihydroxy-5-(1methylethyl)-3-phenyl-4-[(phenylamino)carbonyl]-lH-pyrrole-1heptanoic acid.

Fig. 1: Structure of amlodipine (a) and atorvastatin (b)

The synthetic drug, atorvastatin is generally under the class known statins. These reductase inhibitors are familiar as 3-hydroxyl-3methylglutaryl-coenzyme A (HMG-CoA). All drugs are prescribed for cardiovascular disease and reduction of heart attack, as well as for clinical demand [4-10]. Active pharmaceutical ingredients (APIs) such as amlodipine are commonly manufactured as their acid addition salts to promote solubility and improve both stability and bioavailability. The objective of this review article was to research more about ultraviolet-visible and chromatographic technique's applications, specifically for the quantification of amlodipine and atorvastatin in bulk, pharmaceutical formulations, and biological fluids. Compared the result between all the developed method for amlodipine and atorvastatin about the limit of detection and quantitation value. Discussed briefly the importance of all analytical techniques with respect to cost, time of analysis, sensitivity and limitations.

\section{Analytical Techniques \\ UV-visible spectrophotometer}

Spectroscopic methods are mostly used for the determination of drugs in bulk as well as with pharmaceutical formulations. Ultraviolet (UV) and visible spectrophotometry are important and common techniques for the quantitative analysis of drugs. Because these are low-cost techniques, simple and no requirement of pretreatment as well as any elaborate preparatory step prior to assay. The visible spectrophotometer is depending on the redox and complex formation reaction. However, some deficiencies are also with the techniques with respect to the 
presence of two or more drugs have similar UV characteristic. The detailed literature survey studies elaborate on the advantages and disadvantages among all developed method for both drugs using UVvisible spectrophotometer [11-38] are presented in table 1.

Table 1: Determination of amlodipine and atorvastatin using uv-visible spectrophotometer

\begin{tabular}{|c|c|c|c|c|}
\hline Drug & Reagent/Solvent & $\lambda_{\max }(\mathrm{nm})$ & Application & Reference \\
\hline Amlodipine & Chloramin-T & 390 & Bulk powder & {$[11]$} \\
\hline \multirow[t]{17}{*}{ Besylate } & Methanol & 239,238 & Bulk drug and tablets & [12] \\
\hline & Ethanol & 343 & Rat plasma & [13] \\
\hline & Water & 238 & Tablets & [14] \\
\hline & Methanol, $\mathrm{HCl}$ & 240 & Tablets & [15] \\
\hline & $\begin{array}{l}\text { 7,7,8,8-tetracyanoquinodimethane } \\
\text { (TCNQ), tetracyanoethylene (TCNE) }\end{array}$ & 745,396 & Pure and dosage form & [16] \\
\hline & Phosphoric acid and water & 366 & Pure and dosage form & [17] \\
\hline & Methanol & 360 & Pharmaceutical dosage forms & [18] \\
\hline & $\mathrm{HCl}$ & 239 & Bulk and tablets & [19] \\
\hline & Methanol & 360 & Bulk and tablet dosage form & {$[20]$} \\
\hline & Methanol & $200-350$ & Tablets & {$[21]$} \\
\hline & Methanol & 359 & Bulk mixture and tablets & [22] \\
\hline & Methanol & 360 & Tablets & [23] \\
\hline & Methanol: Water $(50: 50, \mathrm{v} / \mathrm{v})$ & 241 & Tablet & {$[24]$} \\
\hline & Methanol and water & 239,245 & Tablet dosage form & {$[25]$} \\
\hline & Urea solution & 243 & Bulk and pharmaceutical dosage form & [26] \\
\hline & Water & 366,239 & Pure sample and tablets & [27] \\
\hline & Methanol & 239 & Tablet dosage form & [28] \\
\hline Atorvastatin & Methanol & 247 & Pure and tablets & [29] \\
\hline \multirow[t]{10}{*}{ Calcium } & p-dimethylaminobenzaldehyde & 540 & Bulk and dosage form & {$[30]$} \\
\hline & Pararosaniline $\mathrm{HCl}$ & 547 & Tablet & {$[31]$} \\
\hline & Iodine & 291,360 & Pure and pharmaceutical formulations & {$[32]$} \\
\hline & ACN: Water $=70: 30, v / v$ & 268,245 & Tablet dosage form & {$[33]$} \\
\hline & Methanol & 247 & Bulk and pharmaceutical dosage form & [34] \\
\hline & Methanol & 244 & API and tablet & {$[35]$} \\
\hline & Methanol & 246 & Tablet dosage form & {$[36]$} \\
\hline & Methanol: Water $(50: 50, \mathrm{v} / \mathrm{v})$ & 250 & Tablet & {$[24]$} \\
\hline & Urea, Ferric chloride and potassium ferricyanide & 240,787 & Tablets and biological fluids & [37] \\
\hline & Methanol & 246 & API and pharmaceutical formulations & [38] \\
\hline
\end{tabular}

\section{High performance liquid chromatography}

High-performance liquid chromatography (HPLC) technique is more accurate and based on the properties of the analyte with the existing mobile phase and stationary phase. Depending on the stationary and mobile phase, different types of chromatography techniques are developed. Recently high-performance liquid chromatography has achieved lots of attention in the field of pharmaceutical analysis in dosage forms and biological fluids because of its simplicity, sensitivity and high specificity. The conventional rule for the analysis of polar compounds by utilizing a non-polar stationary phase with the polar mobile phase and vice versa for the non-polar compounds. Stationary phase binding the analyte is directly proportional with the surface area of the nonpolar segment of the analyte associate the ligand as well as with aqueous eluent. One of the main parameters found as evidence about the quality and efficacy of drug products and formulations is stability testing. The products nature is changing with humidity, temperature, light, retesting time, storage conditions, shelf life, so it is necessary to control the environmental factors. To develop method different types of the column (ODS $\mathrm{C}_{18}$, BDS $\mathrm{C}_{8}$, ODS $\mathrm{C}_{8}$, BDS $\mathrm{C}_{18}$ and Discovery HS $\mathrm{C}_{18}$ ) with a combination of different mobile phases containing buffers, organic modifier (acetonitrile, methanol) can be used. Amlodipine and atorvastatin were quantified using HPLC with ultraviolet in bulk and pharmaceutical dosage form [39-83] (table 2).

\section{Ultra pressure liquid chromatography}

The ultra-performance liquid chromatography (UPLC) is a new and modern technique for liquid chromatography. Worldwide HPLC was a predominant technique for the last 30 to $40 \mathrm{y}$ for the drug analysis. Speed, sensitivity, and resolution are the main keywords for the drugs analysis with UPLC compare to HPLC. The particle size can play a significant role in this type of chromatography that governed by the well-known Van Deemter equation. For UPLC, the preferred size diameter is less than $2 \mu \mathrm{m}$ to get more sensitivity, short analysis time and improved resolution. The quality of the product analyzed by UPLC will give better with less time. However, the main disadvantage is related to the column life. The analysis requiring high pressure $(100 \mathrm{M} \mathrm{Pa})$ that damage the column efficiency. The novel and selective methods were developed for the determination of both drugs with a marketed formulation as single or combined dosage form [84-98] (table 3).

\section{Thin layer chromatography}

Thin-layer chromatography (TLC) is a simple separation technique typically for the mixture of nonvolatile compounds. The adsorbent material, specifically cellulose, silica gel, aluminum oxide is covered on plastic or glass sheet, known as the stationary phase. Aleppo bentonite with modified phenyl support can also be applied as the stationary phase, has the ability to separate amlodipine and atorvastatin with a mobile phase consisting of sodium phosphate buffer and acetonitrile $(50: 45, \mathrm{v} / \mathrm{v})$ in pharmaceutical dosage form [99]. Methanol, toluene triethylamine combination and silica gel adsorbent distinct atorvastatin in pharmaceutical formulation with high resolution [100]. However, triethylamine can be replaced with chloroform and acetic acid in tablet dosage form on the aluminum plate [101]. However, propanol and water system $(70: 30, v / v)$ has the capability to separate amlodipine with a detection limit of $0.4 \mu \mathrm{g}$ [102]. 
Table 2: Important parameters for the determination of drugs using HPLC

\begin{tabular}{|c|c|c|c|c|c|c|}
\hline Drug & Mobile phase & Stationary phase & $\begin{array}{l}\text { Flow rate } \\
(\mathrm{ml} / \mathrm{min})\end{array}$ & $\begin{array}{l}\text { Detector } \\
\text { (nm) }\end{array}$ & Application & Reference \\
\hline \multirow[t]{19}{*}{$\begin{array}{l}\text { Amlodipine } \\
\text { Besylate }\end{array}$} & $\begin{array}{l}\text { TEA buffer }(\mathrm{pH} 3) \text { and } \mathrm{ACN}=25: 75 \\
\mathrm{v} / \mathrm{v}\end{array}$ & $\begin{array}{l}\text { Stainless steel } \mathrm{C}_{18} \\
(4.6 \times 150 \mathrm{~mm}, 5 \mu \mathrm{m})\end{array}$ & 1.0 & 258 & $\begin{array}{l}\text { Pure and } \\
\text { pharmaceutical } \\
\text { dosage form }\end{array}$ & [39] \\
\hline & $0.1 \%$ OPA: Acetonitrile $=70: 30, \mathrm{v} / \mathrm{v}$ & $\begin{array}{l}\text { Phenomenex } \mathrm{C}_{18} \\
(4.6 \times 100 \mathrm{~mm}, 3.5 \mu \mathrm{m})\end{array}$ & 0.7 & 230 & $\begin{array}{l}\text { Pharmaceutical } \\
\text { dosage form }\end{array}$ & {$[40]$} \\
\hline & $\begin{array}{l}\text { Phosphate Buffer }(\mathrm{pH} 4.5) \text { : } \\
\text { Acetonitrile }=55: 45, \mathrm{v} / \mathrm{v}\end{array}$ & $\begin{array}{l}\text { Phenomenex } \mathrm{C}_{18} \\
(25 \times 0.46 \mathrm{~cm}, 5 \mu \mathrm{m})\end{array}$ & 1.0 & 224 & Tablet & {$[41]$} \\
\hline & $\begin{array}{l}\text { Potassium dihydrogen phosphate } \\
\text { buffer (pH 5.3): Acetonitrile = 55:45, } \\
\text { v/v }\end{array}$ & $\begin{array}{l}\text { Shodex RP C } 18(250 \times 4.6 \\
\mathrm{mm}, 5 \mu \mathrm{m})\end{array}$ & 1.0 & 237 & $\begin{array}{l}\text { Pure and dosage } \\
\text { form }\end{array}$ & [42] \\
\hline & $\begin{array}{l}\text { Ammonium acetate }(0.5 \mathrm{M}, \mathrm{pH} 6.8 \text { at } \\
0.5): \text { Acetonitrile }=40: 60, \mathrm{v} / \mathrm{v}\end{array}$ & $\begin{array}{l}\text { Eclipse XDB } C_{18}(4.6 \times 250 \\
\mathrm{mm}, 5 \mu \mathrm{m})\end{array}$ & 0.5 & 239 & $\begin{array}{l}\text { Bulk drug and } \\
\text { excipient }\end{array}$ & [43] \\
\hline & $\begin{array}{l}\text { Potassium dihydrogen } \\
\text { orthophosphate }(0.05 \mathrm{M}, \mathrm{pH} 3.5) \text { : } \\
\text { Acetonitrile }=45: 55, \mathrm{v} / \mathrm{v}\end{array}$ & $\begin{array}{l}\mathrm{C}_{18} \text { ODS }(250 \times 4.6 \mathrm{~mm} \\
5.0 \mu \mathrm{m})\end{array}$ & 1.5 & 230 & $\begin{array}{l}\text { Pharmaceutical } \\
\text { formulation }\end{array}$ & [44] \\
\hline & $\begin{array}{l}\text { Phosphoric acid }(0.025 \mathrm{M}) \text { and } \\
\text { Acetonitrile }\end{array}$ & $\begin{array}{l}\text { Zorbax SB-C }{ }_{8}(4.6 \times 250 \\
\mathrm{mm}, 5 \mu \mathrm{m})\end{array}$ & 1.0 & $\begin{array}{l}225 \\
238\end{array}$ & Tablets & [45] \\
\hline & $\begin{array}{l}\text { Phosphate buffer: Methanol (73:27, } \\
\text { v/v) }\end{array}$ & $\begin{array}{l}\text { Zorbax Eclipse Plus } \\
(150 \times 4.6 \mathrm{~mm}, 5 \mu \mathrm{m})\end{array}$ & 1.1 & 270 & Tablets & [46] \\
\hline & $\begin{array}{l}\text { Mobile phase A-Phosphate buffer, } \mathrm{pH} \\
\text { 2.8: Methanol=60:40, v/v } \\
\text { Mobile phase B-Phosphate buffer, } \mathrm{pH} \\
\text { 2.8: Methanol: Acetonitrile } \\
=20: 40: 40, \mathrm{v} / \mathrm{v} / \mathrm{v}\end{array}$ & $\begin{array}{l}\text { Inertsil ODS- } 3 \mathrm{C}_{18} \\
(150 \times 4.6 \mathrm{~mm}, 3 \mu \mathrm{m})\end{array}$ & 1.0 & 340 & Tablet formulation & {$[47]$} \\
\hline & $\begin{array}{l}\text { Phosphate buffer }(\mathrm{pH}=3): \\
\text { Acetonitrile: Methanol = } \\
25: 45: 30, \mathrm{v} / \mathrm{v} / \mathrm{v}\end{array}$ & $\begin{array}{l}\text { Zorbax ODS }(4.6 \times 250 \\
\mathrm{mm}, 5 \mu \mathrm{m})\end{array}$ & 1.0 & 254 & Tablets & [48] \\
\hline & Acetonitrile=Methanol $(70: 30, \mathrm{v} / \mathrm{v})$ & $\begin{array}{l}\text { Hypersil } C_{18}(250 \times 4.60 \\
\mathrm{mm}, 5 \mu \mathrm{m})\end{array}$ & 1.0 & 222 & $\begin{array}{l}\text { Bulk and } \\
\text { pharmaceutical } \\
\text { dosage form }\end{array}$ & [49] \\
\hline & $\begin{array}{l}\text { Potassium dihydrogen phosphate } \\
\text { (pH 5.5, 0.03M)-Acetonitrile (65:35, } \\
\text { v/v) }\end{array}$ & $\begin{array}{l}\text { Phenomenex } \mathrm{C}_{18} \\
(250 \times 4.6 \mathrm{~mm}, 2.6 \mu \mathrm{m})\end{array}$ & 1.2 & 240 & Tablets & {$[50]$} \\
\hline & $\begin{array}{l}\text { Potassium dihydrogen } \\
\text { orthophosphate buffer }(50 \mathrm{mmol}, \mathrm{pH} \\
\text { 3.7): Acetonitrile }=(56: 44, \mathrm{v} / \mathrm{v})\end{array}$ & $\begin{array}{l}\text { Kromasil KR } 5 \mathrm{C}_{18} \\
(250 \times 4.6 \mathrm{~mm}, 5 \mu \mathrm{m})\end{array}$ & 1.0 & 232 & $\begin{array}{l}\text { Pharmaceutical } \\
\text { formulations }\end{array}$ & {$[51]$} \\
\hline & $\begin{array}{l}\text { Potassium dihydrogen } \\
\text { orthophosphate buffer }(\mathrm{pH} \\
\text { 3.2):Acetonitrile=(60:40, v/v) }\end{array}$ & $\begin{array}{l}\text { Hypersil gold } \mathrm{C}_{18} \\
(250 \times 4.6 \mathrm{~mm}, 5 \mu \mathrm{m})\end{array}$ & 1.0 & 237 & $\begin{array}{l}\text { Pharmaceutical } \\
\text { dosage form }\end{array}$ & {$[52]$} \\
\hline & $\begin{array}{l}\text { Acetonitrile, water and potassium } \\
\text { dihydrogen phosphate buffer } \mathrm{pH} 2.7 \\
(45: 35: 20, \mathrm{v} / \mathrm{v} / \mathrm{v})\end{array}$ & $\begin{array}{l}\text { Phenomenex Luna } \\
(250 \times 4.60 \mathrm{~mm}, 5 \mu \mathrm{m})\end{array}$ & 1.0 & 230 & Tablet dosage form & {$[53]$} \\
\hline & $\begin{array}{l}\text { Acetonitrile-Phosphate buffer }(0.05 \\
\mathrm{M}, \mathrm{pH} 2.8): \text { Acetonitrile }(60: 40, \mathrm{v} / \mathrm{v})\end{array}$ & $\begin{array}{l}\text { Phenomenex Kinetex } \\
(150 \times 4.6 \mathrm{~mm})\end{array}$ & 0.8 & 227 & $\begin{array}{l}\text { Tablet and human } \\
\text { plasma }\end{array}$ & {$[54]$} \\
\hline & $\begin{array}{l}\text { Phosphate buffer pH 4.0: Acetonitrile } \\
(40: 60, \mathrm{v} / \mathrm{v})\end{array}$ & $\begin{array}{l}\text { ODS } \mathrm{C}_{18}(250 \mathrm{~mm} \times 4.6 \\
\mathrm{mm}, 5 \mu \mathrm{m})\end{array}$ & 1.0 & 247 & $\begin{array}{l}\text { Bulk and tablet } \\
\text { dosage form }\end{array}$ & [55] \\
\hline & $\begin{array}{l}\text { Potassium dihydrogen phosphate } \\
\text { buffer }(\mathrm{pH} 4.5): \text { Methanol } \\
(25: 75, \mathrm{v} / \mathrm{v})\end{array}$ & $\begin{array}{l}\text { Prontosil } \mathrm{C}_{18}(250 \times 4.6 \\
\mathrm{mm}, 5 \mu \mathrm{m})\end{array}$ & 1.4 & 240 & Tablet formulation & {$[56]$} \\
\hline & Acetonitrile and water $(60: 40, \mathrm{v} / \mathrm{v})$ & $\begin{array}{l}\text { HIQ SII } C_{18}-10(250 \times 4.5 \\
\mathrm{mm})\end{array}$ & 1.0 & 248 & Tablet & [57] \\
\hline \multirow[t]{9}{*}{$\begin{array}{l}\text { Atorvastatin } \\
\text { Calcium }\end{array}$} & $\begin{array}{l}\text { Ammonium acetate buffer }(10 \mathrm{mmol} \text {, } \\
\mathrm{pH} 4) \text { : Acetonitrile }(40: 60, \mathrm{v} / \mathrm{v})\end{array}$ & $\begin{array}{l}\text { Symmetry } \mathrm{C}_{18}(75 \times 4.6 \\
\mathrm{mm}, 3.5 \mu \mathrm{m})\end{array}$ & $1.0,2.0$ & 220 & Tablet dosage form & {$[58]$} \\
\hline & $\begin{array}{l}\text { Potassium dihydrogen } \\
\text { orthophosphate buffer }(\mathrm{pH} \\
\text { 3.2):Acetonitrile }=(52: 48, \mathrm{v} / \mathrm{v})\end{array}$ & $\begin{array}{l}\text { Kromasil } C_{18}(150 \times 4.6 \\
\mathrm{mm}, 5 \mu \mathrm{m})\end{array}$ & 1.0 & 210 & Tablet dosage form & [59] \\
\hline & $\begin{array}{l}\text { Acetonitrile: dichloromethane: acetic } \\
\text { acid }(68.6: 30.6: 0.8, \mathrm{v} / \mathrm{v} / \mathrm{v})\end{array}$ & $\begin{array}{l}\text { Acclaim } 120 \mathrm{C}_{18} \\
(250 \times 4.6 \mathrm{~mm}, 5 \mu \mathrm{m})\end{array}$ & 1.0 & 246 & $\begin{array}{l}\text { Pharmaceutical } \\
\text { formulations }\end{array}$ & {$[60]$} \\
\hline & $\begin{array}{l}0.01 \mathrm{~N} \text { Sodium dihydrogen ortho } \\
\text { phosphate buffer }(\mathrm{pH} 4): \text { Methanol = } \\
50: 50, \mathrm{v} / \mathrm{v}\end{array}$ & $\begin{array}{l}\text { Kromasil } \mathrm{C}_{18}(150 \times 4.6 \\
\mathrm{mm}, 5 \mu \mathrm{m})\end{array}$ & 1.0 & 240 & Tablet dosage form & {$[61]$} \\
\hline & $\begin{array}{l}\text { Water }(\mathrm{pH} 4.5 \text {, adjusted with } \\
\text { phosphoric acid): Acetonitrile = } \\
15: 85, \mathrm{v} / \mathrm{v}\end{array}$ & $\begin{array}{l}\text { Zorbax SB C } 18(150 \times 4.6 \\
\mathrm{mm}, 3.5 \mu \mathrm{m})\end{array}$ & 1.0 & 261 & Tablet formulation & {$[62]$} \\
\hline & $\begin{array}{l}\text { Phosphate buffer }(\mathrm{pH}=3): \\
\text { Acetonitrile: Methanol = } \\
25: 45: 30, \mathrm{v} / \mathrm{v} / \mathrm{v}\end{array}$ & $\begin{array}{l}\text { Zorbax ODS }(4.6 \times 250 \\
\mathrm{mm}, 5 \mu \mathrm{m})\end{array}$ & 1.0 & 254 & Tablets & [48] \\
\hline & $\begin{array}{l}\text { Potassium dihydrogen phosphate }(10 \\
\mathrm{Mm}, \mathrm{pH} 3): \text { Acetonitrile }=59: 41, \mathrm{v} / \mathrm{v}\end{array}$ & $\begin{array}{l}\text { Kromasil } 100 \mathrm{C}_{18} \\
(250 \times 4.6 \mathrm{~mm}, 5 \mu \mathrm{m})\end{array}$ & 1.0 & 245 & Tablets & [63] \\
\hline & $\begin{array}{l}\text { Ammonium dihydrogen phosphate } \\
\text { buffer }(\mathrm{pH} \mathrm{5):} \mathrm{Methanol} \mathrm{=} \mathrm{60:40,} \mathrm{v/v}\end{array}$ & $\begin{array}{l}\text { Grace } C_{18}(250 \times 4.66 \mathrm{~mm}, \\
5 \mu \mathrm{m})\end{array}$ & 1.0 & 240 & $\begin{array}{l}\text { Pharmaceutical } \\
\text { dosage form }\end{array}$ & {$[64]$} \\
\hline & Phosphate buffer (pH 3.3): & Agilent XDB C $18(150 \times 4.6$ & 1.0 & 280 & Bulk and & [65] \\
\hline
\end{tabular}




\begin{tabular}{|c|c|c|c|c|c|}
\hline Acetonitrile $=30: 70, \mathrm{v} / \mathrm{v}$ & $\mathrm{mm}, 5 \mu \mathrm{m})$ & & & $\begin{array}{l}\text { pharmaceutical } \\
\text { dosage form }\end{array}$ & \\
\hline $\begin{array}{l}\text { Buffer (pH 5):Acetonitrile }=(60: 40 \text {, } \\
\mathrm{v} / \mathrm{v})\end{array}$ & $\begin{array}{l}\text { Grace } C_{18}(150 \times 4.66 \mathrm{~mm} \text {, } \\
5 \mu \mathrm{m})\end{array}$ & 1.0 & 240 & $\begin{array}{l}\text { Pharmaceutical } \\
\text { dosage form }\end{array}$ & {$[66]$} \\
\hline $\begin{array}{l}\text { Orthophosphoric acid } \\
(0.1 \%): \text { Acetonitrile }=66: 34, \mathrm{v} / \mathrm{v}\end{array}$ & $\begin{array}{l}\text { Kromasil } 100 \mathrm{C}_{18}(25 \\
\mathrm{cm} \times 4.6 \mathrm{~mm}, 5 \mu \mathrm{m})\end{array}$ & 1.0 & 246 & Bulk and tablets & {$[67]$} \\
\hline $\begin{array}{l}\text { Solvent } \mathrm{A}-10 \mathrm{mmol} \text { Phosphoric acid } \\
\text { buffer }(\mathrm{pH}=2.6)\end{array}$ & $\begin{array}{l}\text { BDS Hypersil C } 18 \\
(250 \times 4.6 \mathrm{~mm}, 5 \mu \mathrm{m})\end{array}$ & 1.0 & 220 & Human plasma & {$[68]$} \\
\hline $\begin{array}{l}\text { Potassium dihydrogen phosphate } \\
(\mathrm{pH} 4.5) \text { : Acetonitrile }=30: 70, \mathrm{v} / \mathrm{v}\end{array}$ & $\begin{array}{l}\text { Inertsil } \mathrm{C}_{18} \text { ODS }(4.6 \times 250 \\
\mathrm{mm}, 5 \mathrm{~mm})\end{array}$ & 1.0 & 254 & Tablet dosage form & [69] \\
\hline $\begin{array}{l}\text { Potassium dihydrogen phosphate } \\
(\mathrm{pH} 5.5,0.03 \mathrm{M}) \text {-Acetonitrile = } \\
(65: 35, \mathrm{v} / \mathrm{v})\end{array}$ & $\begin{array}{l}\text { Phenomenex } C_{18} \\
(250 \times 4.6 \mathrm{~mm}, 2.6 \mu \mathrm{m})\end{array}$ & 1.2 & 240 & Tablets & {$[50]$} \\
\hline $\begin{array}{l}\text { Acetic acid solution }(0.1 \%, \mathrm{pH} 3.8) \text { : } \\
\text { Acetonitrile }=45: 55 \mathrm{v} / \mathrm{v}\end{array}$ & $\begin{array}{l}\text { Cartridge-LiChroCARTR } \\
(250 \times 4 \text { mm }) \text { Column- } \\
\text { LiChrospher } 100 \text { RP-18, } \\
5 \mu \mathrm{m}\end{array}$ & 0.8 & 246 & Tablets & {$[70]$} \\
\hline $\begin{array}{l}\text { Potassium dihydrogen } \\
\text { orthophosphate buffer }(0.025 \mathrm{M}, \mathrm{pH} \\
5): \text { Acetonitrile }=55: 45 \mathrm{v} / \mathrm{v}\end{array}$ & $\begin{array}{l}\text { Eclipse XDB ( } 4.6 \times 150 \\
\mathrm{~mm}, 5 \mu \mathrm{m})\end{array}$ & 1.5 & 246 & $\begin{array}{l}\text { Pharmaceutical } \\
\text { formulations }\end{array}$ & {$[71]$} \\
\hline $\begin{array}{l}\text { Acetonitrile: Phosphate buffer }(10 \\
\text { mmol, } \mathrm{pH} \text { 3): Acetonitrile }=45: 55 \mathrm{v} / \mathrm{v}\end{array}$ & $\begin{array}{l}\text { Altima } C_{18}(25 \mathrm{~cm} \times 4.6 \\
\mathrm{mm}, 5 \mu \mathrm{m})\end{array}$ & 1.0 & 240 & $\begin{array}{l}\text { Bulk and dosage } \\
\text { form }\end{array}$ & {$[72]$} \\
\hline $\begin{array}{l}\mathrm{KH}_{2} \mathrm{PO}_{4}(50 \mathrm{mmol}, \mathrm{pH} 4.1): \\
\text { Acetonitrile }=28: 72 \mathrm{v} / \mathrm{v}\end{array}$ & $\begin{array}{l}\text { Capcell pak } C_{8}(4.6 \times 250 \\
\mathrm{mm}, 5 \mu \mathrm{m})\end{array}$ & 1.0 & 260 & $\begin{array}{l}\text { Pharmaceutical } \\
\text { dosage form }\end{array}$ & [73] \\
\hline $\begin{array}{l}\text { Ammonium acetate buffer }(\mathrm{pH} 3) \text { : } \\
\text { Acetonitrile }=50: 50, \mathrm{v} / \mathrm{v}\end{array}$ & $\begin{array}{l}\text { Phenomenex } \mathrm{C}_{18} \\
(250 \times 4.6 \mathrm{~mm}, 5 \mu \mathrm{m})\end{array}$ & 1.2 & 247 & $\begin{array}{l}\text { Pharmaceutical } \\
\text { formulation }\end{array}$ & {$[74]$} \\
\hline $\begin{array}{l}\text { Potassium dihydrogen phosphate } \\
\text { (0.02 M) buffer: Methanol: } \\
\text { Acetonitrile }=10: 50: 40, \mathrm{v} / \mathrm{v} / \mathrm{v}\end{array}$ & $\begin{array}{l}\text { Zorbax SB C } 18(250 \times 4.6 \\
\mathrm{mm}, 5 \mu \mathrm{m})\end{array}$ & 1.1 & 236 & $\begin{array}{l}\text { API and } \\
\text { formulations }\end{array}$ & {$[75]$} \\
\hline $\begin{array}{l}\text { Potassium dihydrogen phosphate }(10 \\
\mathrm{mmol}, \mathrm{pH} 3.0): \text { Acetonitrile }=60: 40 \\
\mathrm{v} / \mathrm{v}\end{array}$ & $\begin{array}{l}\text { Waters } C_{18}(250 \times 4.6 \mathrm{~mm} \text {, } \\
5 \mu \mathrm{m})\end{array}$ & 1.0 & 246 & $\begin{array}{l}\text { Pharmaceutical } \\
\text { tablet formulations }\end{array}$ & [76] \\
\hline $\begin{array}{l}\text { Water (pH } 3.2 \text { with phosphoric acid): } \\
\text { Methanol = } 10: 90, \mathrm{v} / \mathrm{v}\end{array}$ & $\mathrm{HiQ} \mathrm{Sil} \mathrm{C}_{8}(4.6 \times 250 \mathrm{~mm})$ & 1.0 & 260 & Tablet dosage form & {$[77]$} \\
\hline $\begin{array}{l}\text { Sodium phosphate buffer }(0.05 \mathrm{M}, \mathrm{pH} \\
\text { 4.1): } \mathrm{methanol}=30: 70, \mathrm{v} / \mathrm{v}\end{array}$ & $\begin{array}{l}\text { LiChrosphera } C_{18} \\
(250 \times 4.6 \mathrm{~mm}, 5 \mathrm{~mm})\end{array}$ & 1.0 & 247 & $\begin{array}{l}\text { Bulk and tablet } \\
\text { formulation }\end{array}$ & {$[78]$} \\
\hline $\begin{array}{l}\text { Acetate buffer ( } \mathrm{pH} 3.7): \text { methanol }= \\
18: 82, \mathrm{v} / \mathrm{v}\end{array}$ & $\begin{array}{l}\text { Luna }_{18}(250 \times 4.6 \mathrm{~mm}, \\
5 \mu \mathrm{m})\end{array}$ & 1.5 & 248 & Tablet dosage form & [79] \\
\hline $\begin{array}{l}\text { Ammonium acetate buffer }(0.01 \mathrm{M} \text {, } \\
\text { pH 3): Acetonitrile }=50: 50, \mathrm{v} / \mathrm{v}\end{array}$ & $\begin{array}{l}\text { Inertsil ODS }(250 \\
\mathrm{mm} \times 4.6 \mathrm{~mm}, 5 \mu \mathrm{m})\end{array}$ & 1.0 & 254 & $\begin{array}{l}\text { Pharmaceutical } \\
\text { formulations }\end{array}$ & {$[80]$} \\
\hline $\begin{array}{l}\text { Potassium dihydrogen phosphate } \\
\text { buffer }(0.02 \mathrm{M}, \mathrm{pH} 4): \text { methanol = } \\
20: 80, \mathrm{v} / \mathrm{v}\end{array}$ & $\begin{array}{l}\text { Phenomenex } C_{18} \\
(250 \times 4.6 \mathrm{~mm}, 5 \mu \mathrm{m})\end{array}$ & 1.0 & 240 & $\begin{array}{l}\text { Capsule dosage } \\
\text { form }\end{array}$ & {$[81]$} \\
\hline $\begin{array}{l}\text { Water ( } \mathrm{pH} 2 \text { with phosphoric acid): } \\
\text { Acetonitrile }=48: 52, \mathrm{v} / \mathrm{v}\end{array}$ & $\begin{array}{l}\text { LiChrospher ODS, } \\
\text { LiChrosorb ODS, } \\
\text { Spherisorb ODS and } \\
\text { Hypersil OS } \mathrm{C}_{18}\end{array}$ & 1.5 & 245 & $\begin{array}{l}\text { Pharmaceutical } \\
\text { dosage forms }\end{array}$ & {$[82]$} \\
\hline $\begin{array}{l}\text { Ammonium acetate buffer }(\mathrm{pH} 4): \\
\text { Acetonitrile: } \mathrm{THF}=70: 25: 5, \mathrm{v} / \mathrm{v} / \mathrm{v}\end{array}$ & $\begin{array}{l}\text { Luna }_{18}(250 \times 4.6 \mathrm{~mm}, \\
5 \mu \mathrm{m})\end{array}$ & 1.0 & 248 & $\begin{array}{l}\text { Bulk drug and } \\
\text { tablets }\end{array}$ & {$[83]$} \\
\hline
\end{tabular}

\section{High-performance thin layer chromatography}

High-performance thin layer chromatography (HPTLC) is an accelerated separation technique and flexible enough to determine the drug sample. The advantages associated with HPTLC are a short analysis time for the complex sample without pretreatment, independent construction of chromatogram with multiple samples, easy to transfer samples that will increase the confidence and reliability of the technique. It can be employed for qualitative and quantitative purposes. Several combinations of mobile phases with different size of plates have been successfully studied by HPTLC in pharmaceutical preparations [103-115] (table 4).

\section{Capillary electrophoresis}

Capillary electrophoresis (CE) is based on charge and size under electric field separate molecules. The capillary tube is made of glass loaded with an electrolyte solution. Electrophoretic mobility is an important parameter for the separation, chemical constituents as well as solvent viscosity. However, the limitation with gel electrophoresis with regards to applied voltage due to ohmic heating damage the gels and restrict the separation. Need to require large voltage often 10-20 thousand for experiments with CE. Different types of capillary electrophoresis are capillary zone electrophoresis (CZE), capillary gel electrophoresis (CGE), micellar electrokinetic capillary chromatography (MEKC), capillary electro chromatography (CEC), capillary isoelectric focusing (CIEF) and capillary isotachophoresis (CITP).

Phosphate buffer ( $\mathrm{pH}$ 6.5) and methanol mixture combined (80:20, v/v) used as background electrolyte with capillary fused silica column under $15 \mathrm{KV}$ voltage at room temperature for the determination amlodipine and atorvastatin [116]. In tablet formulation no interference from present common excipients [117]. Phosphate buffer can separate both drugs in $5 \mathrm{~min}$ with high precision but in the presence of acidic products need to involve borate buffer [118-119]. It is likewise possible to quantify within $3 \mathrm{~min}$ in combined dosage form with high efficiency and resolution [120]. CZE method validated for solid dosage form in the presence of electrolyte as a methanol borate buffer [121]. MEKC succeeded by controlling surfactant, sodium dodecyl sulfate (SDS) concentration and acquired within 2 min [122] compared to CZE [117] 13 min migration time having comparable resolution. 
Table 3: Determination of amlodipine and atorvastatin in bulk and pharmaceutical formulations using UPLC

\begin{tabular}{|c|c|c|c|c|c|c|c|}
\hline Drug & Mobile phase & $\begin{array}{l}\text { Stationary } \\
\text { phase }\end{array}$ & $\begin{array}{l}\text { Flow rate } \\
(\mathrm{ml} / \mathrm{min})\end{array}$ & $\begin{array}{l}\text { Detector } \\
(\mathrm{nm})\end{array}$ & $\begin{array}{l}\text { Run time } \\
\text { (min) }\end{array}$ & Application & Reference \\
\hline \multirow[t]{8}{*}{$\begin{array}{l}\text { Amlodipine } \\
\text { Besylate }\end{array}$} & $\begin{array}{l}\text { Mobile phase A-Trifluoro acetic } \\
\text { acid in water }(0.1 \%) \text {, Mobile } \\
\text { phase B-Acetonitrile }\end{array}$ & $\begin{array}{l}\mathrm{BEH} \mathrm{C}_{18}(2.1 \times 30 \\
\mathrm{mm}, 1.7 \mu \mathrm{m})\end{array}$ & 0.6 & 246 & 2.5 & $\begin{array}{l}\text { API and } \\
\text { pharmaceutical } \\
\text { dosage forms }\end{array}$ & [84] \\
\hline & $\begin{array}{l}\text { Potassium dihydrogen ortho } \\
\text { phosphate Buffer }(\mathrm{pH} 2.4): \\
\text { Acetonitrile }=40: 60, \mathrm{v} / \mathrm{v}\end{array}$ & $\begin{array}{l}\mathrm{C}_{18}(4.6 \times 50 \\
\mathrm{mm}, 3.5 \mu \mathrm{m})\end{array}$ & 0.5 & 240 & 10.0 & $\begin{array}{l}\text { Tablet dosage } \\
\text { form }\end{array}$ & [85] \\
\hline & $\begin{array}{l}\text { Phosphate buffer }(\mathrm{pH} 3): \\
\text { Acetonitrile }=55: 45, \mathrm{v} / \mathrm{v}\end{array}$ & $\begin{array}{l}\text { Kinetex } \mathrm{C}_{18} \\
(4.6 \times 150 \\
\mathrm{mm}, 2.6 \mu \mathrm{m})\end{array}$ & 1.0 & 230 & 6.0 & Dosage form & {$[86]$} \\
\hline & $\begin{array}{l}\text { Glacial acetic acid (1\%) buffer: } \\
\text { Acetonitrile }=58: 42, \mathrm{v} / \mathrm{v}\end{array}$ & $\begin{array}{l}\mathrm{BEH} \mathrm{C}_{18} 2.1 \times 100 \\
\mathrm{~mm}, 1.7 \mu \mathrm{m})\end{array}$ & 0.25 & 240 & 5.0 & $\begin{array}{l}\text { Tablet dosage } \\
\text { form }\end{array}$ & [87] \\
\hline & $\begin{array}{l}\text { Potassium dihydrogen } \\
\text { phosphate buffer }(0.02 \mathrm{M}) \text { : } \\
\text { Acetonitrile }=45: 55, \mathrm{v} / \mathrm{v}\end{array}$ & $\begin{array}{l}\mathrm{BEH} \mathrm{C}_{18} \\
(100 \times 2.1 \\
\mathrm{mm}, 1.7 \mu \mathrm{m})\end{array}$ & 0.3 & 242 & 5.0 & $\begin{array}{l}\text { Tablet dosage } \\
\text { form }\end{array}$ & [88] \\
\hline & $\begin{array}{l}\text { Triethyl amine buffer }(0.1 \%, \mathrm{pH} \\
\text { 3) and buffer; Gradient elution }\end{array}$ & $\begin{array}{l}\text { Kromasil } \mathrm{C}_{18} \\
(50 \times 2.1 \mathrm{~mm}, 3.5 \\
\mu \mathrm{m})\end{array}$ & 0.8 & 240 & 2.2 & $\begin{array}{l}\text { Pharmaceutical } \\
\text { dosage form }\end{array}$ & [89] \\
\hline & $\begin{array}{l}\text { Mobile phase A-Sodium } \\
\text { perchlorate buffer }(0.053 \mathrm{M}, \mathrm{pH} \\
\text { 3.2): Acetonitrile }=90: 10, \mathrm{v} / \mathrm{v} \\
\text { Mobile phase B-Sodium } \\
\text { perchlorate buffer }(0.053 \mathrm{M}, \mathrm{pH} \\
\text { 3.2): Acetonitrile }=20: 80, \mathrm{v} / \mathrm{v} \\
\text { Gradient programme }\end{array}$ & $\begin{array}{l}\text { BEH RP }_{18} \\
(100 \times 2.1 \\
\mathrm{mm}, 1.7 \mu \mathrm{m})\end{array}$ & 0.6 & 237 & 4.5 & Tablets & [90] \\
\hline & $\begin{array}{l}\text { Mobile phase A: Ammonium } \\
\text { acetate buffer ( } 5 \text { mmol, pH } 4 \text { ) } \\
\text { Mobile phase B: Buffer: } \\
\text { Acetonitrile }(10: 90, \mathrm{v} / \mathrm{v}) \\
\text { Gradient programme }\end{array}$ & $\begin{array}{l}\mathrm{BEH} \mathrm{C}_{18}(50 \times 2.1 \\
\mathrm{mm}, 1.7 \mu \mathrm{m})\end{array}$ & 0.613 & 230 & 3.3 & $\begin{array}{l}\text { Pharmaceutical } \\
\text { dosage form }\end{array}$ & [91] \\
\hline \multirow[t]{8}{*}{$\begin{array}{l}\text { Atorvastatin } \\
\text { Calcium }\end{array}$} & $\begin{array}{l}\text { Ammonium dihydrogen } \\
\text { phosphate buffer }(10 \mathrm{mmol}, \mathrm{pH} \\
\text { 3): Acetonitrile }=50: 50, \mathrm{v} / \mathrm{v}\end{array}$ & $\begin{array}{l}\text { Thermo } \mathrm{C}_{18}(50 \mathrm{x} \\
2.1 \mathrm{~mm}, 1.9 \mu \mathrm{m})\end{array}$ & 0.3 & 255 & 2.5 & Tablet & [92] \\
\hline & $\begin{array}{l}\text { O-phosphoric acid }(1 \%): \\
\text { Acetonitrile }=55: 45, \mathrm{v} / \mathrm{v}\end{array}$ & $\begin{array}{l}\text { Phenomenex } C_{18} \\
(100 \times 4.6 \mathrm{~mm}, \\
2.6 \mu \mathrm{m})\end{array}$ & 1.0 & 254 & 10.0 & Tablets & [93] \\
\hline & $\begin{array}{l}\text { Ammonium acetate buffer }(0.01 \\
\text { M, pH 6.7) and Acetonitrile; } \\
\text { Gradient programme }\end{array}$ & $\begin{array}{l}\text { Kromasil } \mathrm{C}_{18} \\
(2.1 \times 50 \mathrm{~mm}, 2.5 \\
\mu \mathrm{m})\end{array}$ & 0.2 & 245 & 5.0 & $\begin{array}{l}\text { Bulk drug and } \\
\text { tablet }\end{array}$ & [94] \\
\hline & $\begin{array}{l}\text { Triethyl amine buffer }(0.1 \%, \mathrm{pH} \\
\text { 3) and buffer; Gradient } \\
\text { programme }\end{array}$ & $\begin{array}{l}\text { Acquity Kromasil } \\
\mathrm{C}_{18}(50 \times 2.1 \mathrm{~mm} \text {, } \\
3.5 \mu \mathrm{m})\end{array}$ & 0.8 & 240 & 2.2 & $\begin{array}{l}\text { Pharmaceutical } \\
\text { dosage form }\end{array}$ & [89] \\
\hline & $\begin{array}{l}\text { Phosphoric acid }(0.02 \mathrm{M}) \text { buffer } \\
\text { and acetonitrile; Gradient } \\
\text { programme }\end{array}$ & $\begin{array}{l}\text { Zorbax } \mathrm{C}_{18} \\
(50 \times 3.0 \mathrm{~mm}, 1.8 \\
\mu \mathrm{m})\end{array}$ & 0.5 & ----- & 12.0 & Bulk drug & [95] \\
\hline & $\begin{array}{l}\text { Orthophosphoric acid }(0.1 \%) \\
\text { and acetonitrile }=55: 45, \mathrm{v} / \mathrm{v}\end{array}$ & $\begin{array}{l}\mathrm{BEH} \mathrm{C}_{18}(2.1 \times 50 \\
\mathrm{mm}, 1.7 \mu \mathrm{m})\end{array}$ & 0.35 & 230 & 4.0 & $\begin{array}{l}\text { Capsule dosage } \\
\text { form }\end{array}$ & [96] \\
\hline & $\begin{array}{l}\text { Perchloric acid }(0.1 \% \text {, adjusted } \\
\text { to } \mathrm{pH} 2.5) \text { and Acetonitrile; } \\
\text { Gradient programme }\end{array}$ & $\begin{array}{l}\text { BEH } C_{18} \\
(100 \times 2.1 \mathrm{~mm}, 1.7 \\
\mu \mathrm{m})\end{array}$ & 0.6 & 215 & 3.0 & $\begin{array}{l}\text { Tablet dosage } \\
\text { form }\end{array}$ & [97] \\
\hline & $\begin{array}{l}\text { Buffer, ortho phosphoric acid } \\
(0.06 \%) \text { with ion pair reagent } \\
\text { sodium lauryl sulfate }(0.045 \mathrm{M}) \\
\text { and Acetonitrile }=50: 50, \mathrm{v} / \mathrm{v}\end{array}$ & $\begin{array}{l}\text { Zorbax } \mathrm{C}_{18} \\
(4.6 \times 50 \mathrm{~mm}, 1.8 \\
\mu \mathrm{m})\end{array}$ & 1.0 & 210 & 6.0 & $\begin{array}{l}\text { Capsule dosage } \\
\text { form }\end{array}$ & [98] \\
\hline
\end{tabular}

High and ultra-pressure liquid chromatography combined with mass spectrophotometry

High pressure and ultra-performance liquid chromatography with the mass spectrometry (LC-MS, UPLC-MS) are analytical techniques that combine liquid chromatography with mass spectrophotometer. The aim to develop a fast and reliable analytical method for the determination of atorvastatin and amlodipine together with the presence of metabolites using the above techniques. The MS combined with LC has high selectivity and sensitivity. The techniques are commonly applied for bioavailability and pharmacokinetics investigation. Mostly quantification of parent drug, active and inactive metabolites are of interest for various studies with biological fluids. It is also required to verify the interaction between drug to drug and side effects as well as the toxicity of different metabolites after metabolism in the human body. The LCMS [123-136] (table 5) and UPLC-MS [137142] (table 6) were used for the determination of amlodipine, atorvastatin and their metabolites in pharmaceutical dosage forms and biological fluids.

\section{DISCUSSION}

The UV-visible spectrophotometer does not require any $\mathrm{pH}$ adjustment and very close to the pharmacopeia method for both drugs. Recently HPTLC can be applied as an alternative option for traditional TLC method. It is easy to handle with software, which is not possible with TLC. HPTLC enhanced the capability to determine impurity with the help of the hydrophilic phase combined silica gel, an important parameter in all pharmacopoeias. One single run is enough to achieve two parameters such quantity and its impurity by HPLC, main pharmacopeias method to quantify the assay 
percentage. The setting of parameters for the reaction is not easy as well as for characterization with CE that is why maybe not recommended in official method. UPLC is a high-cost instrument compare with other chromatographic methods, ability to study pharmacokinetics such as adsorption, metabolism. The limit of detection (LOD) and limit of quantitation (LOQ) value is very less with chromatographic method combined with mass spectro- photometry (table 7). Amlodipine and atorvastatin concentration in pharmaceutical formulations and biological fluids are based on different parameters and the calibration curve of the analyte (table 8). During method development and validation, accurately quantified the analyte as well provide brief information related to impurity profiling, a key equipment for the formulation process of the drug.

Table 4: Determination of drugs using HPTLC in pharmaceutical preparations

\begin{tabular}{|c|c|c|c|c|c|c|}
\hline Drug & Mobile phase & Stationary phase & $\begin{array}{l}R_{\mathrm{f}} \\
\text { value }\end{array}$ & $\begin{array}{l}\text { Detector } \\
(\mathrm{nm})\end{array}$ & Application & Reference \\
\hline \multirow[t]{7}{*}{$\begin{array}{l}\text { Amlodipine } \\
\text { Besylate }\end{array}$} & $\begin{array}{l}\text { Acetonitrile: Water: Toluene } \\
(60: 30: 10, \mathrm{v} / \mathrm{v} / \mathrm{v})\end{array}$ & $\begin{array}{l}\text { Aluminium plate coated with Silica } \\
\text { Gel } 60 \mathrm{~F}_{254}\end{array}$ & 0.57 & 270 & Tablet formulation & [103] \\
\hline & $\begin{array}{l}\text { Ethyl acetate: Methanol: } \\
\text { Ammonia }(7.5: 2: 0.5, \mathrm{v} / \mathrm{v} / \mathrm{v})\end{array}$ & $\begin{array}{l}\text { Aluminium plate }(20 \times 10 \mathrm{~cm}, 0.2 \\
\text { mm) coated with Silica Gel } 60 \mathrm{~F}_{254}\end{array}$ & 0.50 & 365 & Dosage form & [104] \\
\hline & $\begin{array}{l}\text { Chloroform: Butan-1-ol: } \\
\text { Ammonia (6: } 4: 0.1, \mathrm{v} / \mathrm{v} / \mathrm{v})\end{array}$ & $\begin{array}{l}\text { Aluminium plate }(10 \times 10 \mathrm{~cm} \text {, } \\
\text { washed with methanol) coated } \\
\text { with Silica Gel } 60 \mathrm{~F}_{254}\end{array}$ & 0.27 & 254 & Tablet dosage form & [105] \\
\hline & $\begin{array}{l}\text { Chloroform: Toluene: Methanol: } \\
\text { Acetic acid (6: } 2.5: 1.5: 0.5 \\
\text { v/v/v/v) }\end{array}$ & $\begin{array}{l}\text { Aluminium plates }(10 \times 10 \mathrm{~cm}) \\
\text { precoated with silica gel } 60 \mathrm{~F}_{254}\end{array}$ & 0.3 & 244 & Synthetic mixture & [106] \\
\hline & $\begin{array}{l}\text { Methanol: Toluene: Ethyl acetate: } \\
\text { 10\% Ammonia solution } \\
(2: 3.5: 5: 1, \mathrm{v} / \mathrm{v} / \mathrm{v})\end{array}$ & $\begin{array}{l}\text { Aluminium plates }(10 \times 10 \mathrm{~cm}, 0.2 \\
\mathrm{mm}) \text { precoated with silica gel } \\
60 \mathrm{~F}_{254}\end{array}$ & 0.28 & 237 & $\begin{array}{l}\text { Pharmaceutical } \\
\text { dosage form }\end{array}$ & [107] \\
\hline & $\begin{array}{l}\text { Toluene: Ethyl acetate: Methanol: } \\
\text { Triethylamine }(4: 1: 1: 0.4, \mathrm{v} / \mathrm{v} / \mathrm{v})\end{array}$ & $\begin{array}{l}\text { Aluminium plates }(10 \times 10 \mathrm{~cm}, 0.2 \\
\text { mm) precoated with silica gel } \\
60 \mathrm{~F}_{254}\end{array}$ & 0.39 & 254 & Bulk and tablets & [108] \\
\hline & $\begin{array}{l}\text { Methanol: n-butanol: } 25 \% \\
\text { Ammonia solution }(4: 4: 2, \mathrm{v} / \mathrm{v} / \mathrm{v})\end{array}$ & $\begin{array}{l}\text { Plates }(10 \mathrm{~mm} \text {, bottom and } 10 \mathrm{~mm} \text {, } \\
\text { side edges, band length } 6 \mathrm{~mm}) \\
\text { precoated with silica gel }\end{array}$ & 0.80 & 218 & $\begin{array}{l}\text { Pharmaceutical } \\
\text { dosage form }\end{array}$ & [109] \\
\hline \multirow[t]{7}{*}{$\begin{array}{l}\text { Atorvastatin } \\
\text { Calcium }\end{array}$} & $\begin{array}{l}\text { Chloroform: Methanol: Toluene: } \\
\text { Ammonia (5:2:1:0.2, v/v/v/v) }\end{array}$ & $\begin{array}{l}\text { Aluminium plates }(20 \times 10 \mathrm{~cm}) \\
\text { precoated with silica gel } 60 \mathrm{~F}_{254}\end{array}$ & 0.17 & 289 & Tablet dosage form & [110] \\
\hline & $\begin{array}{l}\text { Ethyl acetate: Methanol: } \\
\text { Ammonia (7.5:2:0.5, v/v/v) }\end{array}$ & $\begin{array}{l}\text { Aluminium plate }(20 \times 10 \mathrm{~cm}, 0.2 \\
\text { mm }) \text { coated with Silica Gel } 60 \mathrm{~F}_{254}\end{array}$ & 0.26 & 365 & Dosage form & [104] \\
\hline & $\begin{array}{l}\text { Toluene: Ethyl acetate: Methanol: } \\
\text { Glacial Acetic Acid (7:2:1:0.1, } \\
\text { v/v/v/v) }\end{array}$ & $\begin{array}{l}\text { Precoated silica gel } 60 \mathrm{~F}_{254} \mathrm{TLC} \\
\text { plates }\left(20 \times 20 \mathrm{~cm}^{2}, 0.2 \mathrm{~mm}\right)\end{array}$ & 0.38 & 262 & $\begin{array}{l}\text { Pharmaceutical } \\
\text { dosage form }\end{array}$ & [111] \\
\hline & Toluene: Methanol $(8: 2, v / v)$ & $\begin{array}{l}\text { Plate precoated with silica gel } 60 \\
\mathrm{~F}_{254}(20 \times 10 \mathrm{~cm}, 0.2 \mathrm{~mm})\end{array}$ & 0.15 & 260 & Dosage form & [112] \\
\hline & $\begin{array}{l}\text { Toluene: Methanol: Ethyl acetate: } \\
\text { Acetic acid (5: 1:1:0.3, v/v/v/v) }\end{array}$ & $\begin{array}{l}\text { Plate coated with silica gel } 60 \mathrm{~F}_{254} \\
(10 \times 10 \mathrm{~cm}, 250 \mathrm{~mm})\end{array}$ & 0.63 & 279 & $\begin{array}{l}\text { Tablet } \\
\text { formulations }\end{array}$ & [113] \\
\hline & $\begin{array}{l}\text { Acetonitrile: Methanol: Ethyl } \\
\text { acetate: Glacial Acetic Acid } \\
(2: 4: 4: 0.06, v / v / v / v)\end{array}$ & $\begin{array}{l}\text { Precoated silica gel } 60 \mathrm{~F}_{254}(10 \times 10 \\
\mathrm{cm}, 0.2 \mathrm{~mm})\end{array}$ & 0.77 & 223 & $\begin{array}{l}\text { Pharmaceutical } \\
\text { dosage form }\end{array}$ & [114] \\
\hline & $\begin{array}{l}\text { Toluene: Methanol: Ethyl } \\
\text { Acetate: Glacial Acetic Acid ( } 7: \\
\text { 1.5: } 1: 0.5, \mathrm{v} / \mathrm{v} / \mathrm{v} / \mathrm{v})\end{array}$ & $\begin{array}{l}\text { Aluminum backed silica gel } 60 \mathrm{~F}_{254} \\
\text { plates }(10 \times 10 \mathrm{~cm})\end{array}$ & 0.28 & 276 & Capsules & [115] \\
\hline
\end{tabular}

Table 5: Determination of drugs in biological fluids using LCMS

\begin{tabular}{|c|c|c|c|c|c|}
\hline Drug & Mobile phase & Stationary phase & $\begin{array}{l}\text { Flow rate } \\
(\mathrm{ml} / \mathrm{min})\end{array}$ & Application & Reference \\
\hline \multirow[t]{8}{*}{$\begin{array}{l}\text { Amlodipine } \\
\text { Besylate }\end{array}$} & $\begin{array}{l}\text { Acetonitrile: Water (10 mmol ammoniumacetate, } 0.5 \% \\
\text { ammonia Solution) }=95: 5, \mathrm{v} / \mathrm{v}\end{array}$ & $\begin{array}{l}\text { Chiralcel OZ-RH } \\
(150 \times 4.6 \mathrm{~mm}, 5 \mu \mathrm{m})\end{array}$ & 0.5 & Rat plasma & {$[123]$} \\
\hline & $\begin{array}{l}\text { Ammonium acetate in } 0.1 \% \text { formic acid: Methanol: } \\
\text { Acetonitrile }=40: 30: 30, \mathrm{v} / \mathrm{v} / \mathrm{v}\end{array}$ & $\begin{array}{l}\text { Zorbax SB C } 18(50 \times 4.6 \\
\mathrm{mm}, 3.5 \mu \mathrm{m})\end{array}$ & 0.7 & $\begin{array}{l}\text { Human } \\
\text { plasma }\end{array}$ & [124] \\
\hline & $\begin{array}{l}\text { Acetonitrile: Ammonium formate }(2 \mathrm{mmol}, \mathrm{pH} 4)=90: 10 \text {, } \\
\mathrm{v} / \mathrm{v}\end{array}$ & $\begin{array}{l}\text { Chromolith RP } 18 \mathrm{e}(100 \\
\mathrm{mm} \times 4.6 \mathrm{~mm})\end{array}$ & $0.5-1.1$ & $\begin{array}{l}\text { Human } \\
\text { plasma }\end{array}$ & {$[125]$} \\
\hline & $\begin{array}{l}\text { Acetonitrile: Water }\left(10 \mathrm{mmol} \mathrm{CH}_{3} \mathrm{COONH}_{4}, \mathrm{pH} 3.0\right)=70: 30 \text {, } \\
\mathrm{v} / \mathrm{v}\end{array}$ & $\begin{array}{l}\text { Zorbax XDB C } 18 \\
(2.1 \times 30 \mathrm{~mm}, 3.5 \mu \mathrm{m})\end{array}$ & 0.15 & $\begin{array}{l}\text { Human } \\
\text { plasma }\end{array}$ & {$[126]$} \\
\hline & Acetonitrile: Formic acid $(10 \mathrm{mmol})=80: 20, \mathrm{v} / \mathrm{v}$ & $\begin{array}{l}\text { Atlantis dC } 18(2.1 \times 100 \\
\mathrm{mm}, 3 \mu \mathrm{m})\end{array}$ & 0.3 & $\begin{array}{l}\text { Human } \\
\text { plasma }\end{array}$ & {$[127]$} \\
\hline & $\begin{array}{l}\text { Acetonitrile: Ammonium formate solution }(5 \mathrm{mmol})=80: 20 \text {, } \\
\mathrm{v} / \mathrm{v}\end{array}$ & $\begin{array}{l}\text { Luna } C_{18} 100 \mathrm{~A} \\
(150 \times 4.6 \mathrm{~mm}, 5 \mu \mathrm{m})\end{array}$ & 0.8 & $\begin{array}{l}\text { Human } \\
\text { plasma }\end{array}$ & {$[128]$} \\
\hline & Acetonitrile: Water $(0.1 \%$ formic acid $)=50: 50, v / v$ & $\begin{array}{l}\text { Aquasil } \mathrm{C}_{18}(50 \times 2.1 \\
\mathrm{mm}, 5 \mu \mathrm{m})\end{array}$ & 0.2 & Rat plasma & {$[129]$} \\
\hline & $\begin{array}{l}\text { Methanol and ammonium acetate }(10 \mathrm{mmol}) \text {; Gradient } \\
\text { programme }\end{array}$ & $\begin{array}{l}\text { Diamond } \mathrm{C}_{18}(150 \times 4.6 \\
\mathrm{mm}, 5 \mu \mathrm{m})\end{array}$ & $0.5-0.8$ & $\begin{array}{l}\text { Human } \\
\text { plasma }\end{array}$ & {$[130]$} \\
\hline \multirow[t]{4}{*}{$\begin{array}{l}\text { Atorvastatin } \\
\text { Calcium }\end{array}$} & $\begin{array}{l}\text { Mobile phase A-Acetonitrile Mobile phase B- } 0.1 \% \mathrm{CH}_{3} \mathrm{COOH} \\
\text { Gradient programme }\end{array}$ & $\begin{array}{l}\text { Zorbax } C_{18}(4.6 \times 100 \\
\mathrm{mm}, 3.5 \mu \mathrm{m})\end{array}$ & 0.4 & Rat plasma & [131] \\
\hline & $\begin{array}{l}\text { Acetonitrile: Water }\left(10 \mathrm{mmol} \mathrm{CH}_{3} \mathrm{COONH}_{4}, \mathrm{pH} 3.0\right)=70: 30 \text {, } \\
\mathrm{v} / \mathrm{v}\end{array}$ & $\begin{array}{l}\text { Zorbax } \mathrm{C}_{18}(2.1 \times 30 \\
\mathrm{mm}, 3.5 \mu \mathrm{m})\end{array}$ & 0.15 & $\begin{array}{l}\text { Human } \\
\text { plasma }\end{array}$ & {$[126]$} \\
\hline & $\begin{array}{l}\text { Water and methanol (modified with } 2 \mathrm{mmol} \text { ammonium } \\
\text { formate and } 0.2 \% \text { formic acid); Gradient programme }\end{array}$ & $\begin{array}{l}\text { Zorbax } C_{18}(50 \times 2.1 \\
\mathrm{mm}, 3.5 \mu \mathrm{m})\end{array}$ & 0.4 & $\begin{array}{l}\text { Human } \\
\text { plasma }\end{array}$ & {$[132]$} \\
\hline & Formic acid $(0.005 \%)$ : Acetonitrile: Methanol $=35: 25: 40$, & Ascentiss $C_{18}(75 \times 4.6$ & 0.6 & Human & [123] \\
\hline
\end{tabular}


$\mathrm{v} / \mathrm{v} / \mathrm{v}$

Formic acid (0.2\%): Acetonitrile $=30: 70, \mathrm{v} / \mathrm{v}$

Acetic acid buffer (0.2\%): Methanol: Acetonitrile $=20: 16: 64$, $\mathrm{v} / \mathrm{v} / \mathrm{v}$

Acetonitrile: Methanol: $0.1 \%$ Formic acid $(0.1 \%)=50: 30$ : $20, \mathrm{v} / \mathrm{v} / \mathrm{v}$

\begin{tabular}{|c|c|c|}
\hline $\mathrm{mm}, 2.7 \mu \mathrm{m})$ & & plasma \\
\hline $\begin{array}{l}\text { Agilent } C_{18}(100 \times 4.6 \\
\mathrm{mm}, 3.5 \mu \mathrm{m})\end{array}$ & 0.6 & $\begin{array}{l}\text { Human } \\
\text { plasma }\end{array}$ \\
\hline $\begin{array}{l}\text { Zorbax Phenyl }(75 \times 4.6 \\
\mathrm{mm}, 3.5 \mu \mathrm{m})\end{array}$ & 0.8 & $\begin{array}{l}\text { Human } \\
\text { plasma }\end{array}$ \\
\hline $\begin{array}{l}\text { Cyno }(125 \times 4 \mathrm{~mm} \text {, } \\
5 \mu \mathrm{m})\end{array}$ & 0.5 & $\begin{array}{l}\text { Human } \\
\text { plasma }\end{array}$ \\
\hline
\end{tabular}

Table 6: Determination of drugs in dosage form and biological sample using UPLC-MS

\begin{tabular}{|c|c|c|c|c|c|c|}
\hline Drug & Mobile phase & Stationary phase & $\begin{array}{l}\text { Flow rate } \\
(\mathrm{ml} / \mathrm{min})\end{array}$ & $\begin{array}{l}\text { Run time } \\
\text { (min) }\end{array}$ & Application & Reference \\
\hline \multirow[t]{4}{*}{$\begin{array}{l}\text { Amlodipine } \\
\text { Besylate }\end{array}$} & $\begin{array}{l}\text { Mobile phase } \mathrm{A}-0.1 \% \text { formic acid in } \\
\text { water }\end{array}$ & $\begin{array}{l}\mathrm{BEH} \mathrm{C}_{18}(2.1 \times 100 \\
\mathrm{mm}, 1.7 \mu \mathrm{m})\end{array}$ & 0.3 & 5.5 & Human plasma & [137] \\
\hline & $\begin{array}{l}\text { Mobile phase B- } 0.1 \% \text { formic acid in } \\
\text { acetonitrile: Methanol = } 90: 10, \mathrm{v} / \mathrm{v}\end{array}$ & & & & & \\
\hline & $\begin{array}{l}\text { Solvent A- } 0.1 \% \text { formic acid in water } \\
\text { Solvent B- } 0.1 \% \text { formic acid in } \\
\text { acetonitrile: water }=95: 5, \mathrm{v} / \mathrm{v}\end{array}$ & $\begin{array}{l}\text { Hypersil }(50 \times 2 \\
\mathrm{mm}, 1.9 \mu \mathrm{m})\end{array}$ & 0.25 & 5.0 & Dosage form & [138] \\
\hline & $\begin{array}{l}0.1 \% \text { formic acid in ammonium acetate } \\
\text { buffer }(0.02 \mathrm{M}, \mathrm{pH} 3.5): \text { Methanol = } \\
25: 75, \mathrm{v} / \mathrm{v}\end{array}$ & $\begin{array}{l}\mathrm{BEH} \mathrm{C}_{18}(50 \times 2.1 \\
\mathrm{mm}, 5 \mu \mathrm{m})\end{array}$ & 0.6 & 10.0 & Human plasma & [139] \\
\hline \multirow[t]{4}{*}{$\begin{array}{l}\text { Atorvastatin } \\
\text { Calcium }\end{array}$} & $\begin{array}{l}0.2 \%(\mathrm{v} / \mathrm{v}) \text { formic acid in water and } \\
\text { acetonitrile, gradient programme }\end{array}$ & $\begin{array}{l}\text { Leapsil } \mathrm{C}_{18} 100 \times 2.1 \\
\mathrm{~mm}, 2.7 \mu \mathrm{m})\end{array}$ & 0.3 & 5.0 & Human plasma & [140] \\
\hline & $\begin{array}{l}0.05 \%(\mathrm{v} / \mathrm{v}) \text { formic acid in water: } \\
\text { Acetonitrile }=25: 75, \mathrm{v} / \mathrm{v}\end{array}$ & $\begin{array}{l}\text { Acquity T3 }(3 \times 100 \\
\mathrm{mm}, 1.8 \mu \mathrm{m})\end{array}$ & 0.3 & 4.0 & Human plasma & [141] \\
\hline & $\begin{array}{l}\text { Solvent } \mathrm{A}-0.1 \% \text { formic acid in water } \\
\text { Solvent B- } 0.1 \% \text { formic acid in } \\
\text { acetonitrile: water }=95: 5, \mathrm{v} / \mathrm{v}\end{array}$ & $\begin{array}{l}\text { Hypersil }(50 \times 2.0 \\
\mathrm{mm}, 1.9 \mu \mathrm{m})\end{array}$ & 0.25 & 5.0 & $\begin{array}{l}\text { Bulk and } \\
\text { dosage form }\end{array}$ & [138] \\
\hline & $\begin{array}{l}\text { Acetonitrile and Ammonium acetate } \\
\text { buffer }(0.05 \mathrm{mmol}, \mathrm{pH} 4) \text {; Gradient } \\
\text { programme }\end{array}$ & $\begin{array}{l}\mathrm{BEH} \mathrm{C}_{18}(100 \times 2.1 \\
\mathrm{mm}, 1.7 \mu \mathrm{m})\end{array}$ & 0.25 & 5.25 & Serum sample & [142] \\
\hline
\end{tabular}

Table 7: Comparison of LOD and LOQ values for amlodipine and atorvastatin with various analytical techniques

\begin{tabular}{|c|c|c|c|c|c|}
\hline Drugs & Analytical technique & Sample/Application & LOD $(\mu \mathrm{g} / \mathrm{ml})$ & LOQ $(\mu \mathrm{g} / \mathrm{ml})$ & Reference \\
\hline \multirow[t]{6}{*}{ Amlodipine Besylate } & UV-Visible & Pure and dosage form & 0.291 & 0.963 & {$[42]$} \\
\hline & HPLC & Pure and dosage form & 0.074 & 0.223 & [42] \\
\hline & UPLC & Tablet dosage form & 0.02 & 0.062 & [88] \\
\hline & $\mathrm{CE}$ & Tablets & 0.13 & 0.44 & [121] \\
\hline & LCMS & Human plasma & $0.302 \mathrm{ng} / \mathrm{ml}$ & $0.997 \mathrm{ng} / \mathrm{ml}$ & [129] \\
\hline & UPLCMS & Dosage form & $0.23 \mathrm{ng} / \mathrm{ml}$ & $0.69 \mathrm{ng} / \mathrm{ml}$ & [139] \\
\hline \multirow{6}{*}{ Atorvastatin Calcium } & UV-Visible & Pharmaceutical formulation & 0.31 & 0.93 & {$[31]$} \\
\hline & HPLC & Tablet dosage form & 0.189 & 0.603 & [58] \\
\hline & UPLC & Tablet dosage form & 0.026 & 0.078 & [88] \\
\hline & $\mathrm{CE}$ & Pharmaceutical formulations & 0.27 & 0.89 & [122] \\
\hline & LCMS & Human plasma & $0.05 \mathrm{ng} / \mathrm{ml}$ & $0.165 \mathrm{ng} / \mathrm{ml}$ & [134] \\
\hline & UPLCMS & Dosage form & $0.56 \mathrm{ng} / \mathrm{ml}$ & $1.7 \mathrm{ng} / \mathrm{ml}$ & [139] \\
\hline
\end{tabular}

Table 8: Advantages and disadvantages between all analytical techniques applied for amlodipine and atorvastatin

\begin{tabular}{|c|c|c|}
\hline $\begin{array}{l}\text { Analytical } \\
\text { technique }\end{array}$ & Disadvantages & Advantages \\
\hline UV-Visible & $\begin{array}{l}\text { Defective equipment designs due to stray light, linearity range } \\
\text { decreases; Quality of detector affected signal measurement and } \\
\text { sensitivity reduced }\end{array}$ & $\begin{array}{l}\text { Simple operation procedure, fast, cost effective, accurate in } \\
\text { readings and used widely }\end{array}$ \\
\hline TLC & $\begin{array}{l}\text { Low reproducibility, inadequate separation length, unavailable } \\
\text { automation, without scanning, less efficiency, only qualitative and } \\
\text { open system }\end{array}$ & $\begin{array}{l}\text { Low cost, easy separation, require small size, visible with UV } \\
\text { light, non-volatile analyte }\end{array}$ \\
\hline HPLC & $\begin{array}{l}\text { Difficult with coelution and adsorbed analyte, necessary mobile } \\
\text { phase filtration, degassing and pH } 8 \text { (basic) impossible for } \\
\text { separation, need high skilled analyst }\end{array}$ & $\begin{array}{l}\text { High resolution, repeatability, reliable data, develop method } \\
\text { can modified with regards to quantification level }\end{array}$ \\
\hline HPTLC & $\begin{array}{l}\text { Glass plate with heavy weight, fragile, excessive cost; } \\
\text { Aluminum plate loses shape above } 120^{\circ} \mathrm{C} \text {, prewashing desired for } \\
\text { plate, concentration dependent spectral shape }\end{array}$ & $\begin{array}{l}\text { Applicable for matrix sample, not require filtration of mobile } \\
\text { phase, can work with pH 8, no contamination, visual } \\
\text { detection, high efficiency, no need high skilled analyst }\end{array}$ \\
\hline UPLC & $\begin{array}{l}\text { Involved high pressure, moderate column life, high maintenance } \\
\text { cost }\end{array}$ & $\begin{array}{l}\text { Highly sensitive, less solvent consumption, small flow rate, } \\
\text { decrease particle size }\end{array}$ \\
\hline CE & $\begin{array}{l}\text { Low repeatability, high cost, problem during characterization of } \\
\text { peak, effect of matrix and parameters optimization for analyte }\end{array}$ & $\begin{array}{l}\text { Able to determine ion, charge, highly polar compound; } \\
\text { different mode of separation, less volume and effluent }\end{array}$ \\
\hline HPLCMS & $\begin{array}{l}\text { Pretreatment of analyte before each analysis, high cost reagent, } \\
\text { complex sample preparation }\end{array}$ & $\begin{array}{l}\text { Rapid analysis, short run time, large no analyte batches, easy } \\
\text { to quantify parent drug and its metabolite }\end{array}$ \\
\hline UPLCMS & $\begin{array}{l}\text { Multi reaction monitoring, equipment cost high and necessary } \\
\text { derivatization }\end{array}$ & $\begin{array}{l}\text { Robust, sensitive, capable of bioequivalence study, easy for } \\
\text { biological fluids, low LOD and LOQ (table 7) }\end{array}$ \\
\hline
\end{tabular}




\section{CONCLUSION}

The main objective of this review is to provide sufficient information for the researcher, academic, scientist about the analysis of important calcium channel and statins receptor. After going through with the proposed review, people can understand the common method for the analysis of drugs. These medications are very significant due to its growing demands in our daily life that is why it was one of the fastest growing products in the pharmaceutical industry. The ultraviolet and visible spectrophotometer are low-cost instrument as well as easy to handle and available everywhere. It is more suitable for pure pharmaceutical formulations. The biological fluids and trace analysis will go for highly sensitive instrument combined with the mass spectrophotometer. Therefore, the present review will give an idea for determination and quantification of both drugs using UV-visible, HPLC, HPTLC, UPLC, LCMS and UPLC-MS in bulk, pharmaceutical formulations, and biological fluids.

\section{AUTHORS CONTRIBUTIONS}

All the author have contributed equally

\section{CONFLICT OF INTERESTS}

The authors report no conflicts of interest

\section{REFERENCES}

1. Triggle DJ. Calcium channel antagonists: clinical uses-past, present and future. Biochem Pharmacol 2007;74:1-9.

2. Chmiel K, Knapik KJ, Jurkiewicz K, Sawicki W, Jachowicz R, Paluch $\mathrm{M}$, et al. A new method to identify physically stable concentration of amorphous solid dispersions (I): case of Flutamide+Kollidon VA64. Mol Pharm 2017;14:3370-80.

3. Kumar DB, Patel J, Chhatoi P, Begum S, Dey S. Analytical method development and validation of amlodipine and benazepril hydrochloride in combined dosage form by RPHPLC. Int J Chem Pharm Sci 2011;2:26-30.

4. Sun S, Wang R, Fan J, Zhang GQ, Zhang H. Effects of danshen tablets on pharmaco kinetics of atorvastatin calcium in rats and its potential mechanism. Pharm Biol 2018;56:104-8.

5. Garza L, Dols J, Gillespie M. An initiative to improve primary prevention of cardiovascular disease in adults with type II diabetes based on the ACC/AHA(2013) and ADA(2016) guidelines. J Am Assoc Nurs Pract 2017;29:606-11.

6. Lampropoulos K, Megalou A, Bazoukis G, Tse G, Manolis A. Preloading therapy with statins in patients with angina and acute coronary syndromes undergoing PCI. J Interv Cardiol 2017;30:507-13.

7. Cruz Correa OF, Leon Cachon RB, Barrera Saldana HA, Soberon $\mathrm{X}$. Prediction of atorvastatin plasmatic concentrations in healthy volunteers using integrated pharmacogenetics sequencing. Pharmacogenomics 2017;18:121-31.

8. Dennison TJ, Smith JC, Badhan RK, Mohammed AR. Fixed-dose combination orally disintegrating tablets to treat cardiovascular disease: formulation, in vitro characterization and physiologically based pharmacokinetic modeling to assess bioavailability. Drug Des Dev Ther 2017;11:811-26.

9. Eng H, Scialis RJ, Rotter CJ, Lin J, Lazzaro S, Varma MV, et al. The antimicrobial agent fusidic acid inhibits organic anion transporting polypeptide-mediated hepatic clearance and may potentiate statin-induced myopathy. Drug Metab Dispos 2016;44:692-9.

10. Virani P, Sojitra R, Raj H, Jain V. A review on irbesartan co administered with atorvastatin for the treatment of cardiac risk. J Crit Rev 2014;1:25-8.

11. Abdulsalam FO, Prema KR, Asha IT. Spectrophotometric study oxidation of amlodipine besylate by chloramine-T in acidic buffer pH (4.3) medium. Der Pharma Chem 2018;10:67-73.

12. Raskar MA, Ganesh RG, Ashok BC, Pritam DG. Validated simultaneous spectrophotometric estimation of telmisartan, hydrochlorthiazide and amlodipine besylate in combined tablet dosage form. Der Pharm Lett 2015;7:120-4.

13. Srinivasulu P, Gowthami BK, Kumar TNVG, Raju DSN, Vidyadhara S. Determination of amlodipine in rat plasma by uv spectroscopy. Indo Global J Pharma Sci 2015;5:205-9.
14. Naveed S, Hina Q, Wardha J, Urooj B. Simple UV spectrophotometric assay of amlodipine. Am J Chem Appl 2014;1:66-9.

15. Manisha M, Abhilasha M, Nandy BC. Spectrophotometric simultaneous estimation of amlodipine besylate and losartan potassium in tablet dosage forms. Asian J Pharm Clin Res 2014;7:61-3.

16. Nina A, Fatimeh H. Spectrophotometric method for the determination of amlodipine besylate in pure and dosage forms using 7,7,8,8-tetracyanoquinodimethane and tetracyanoethylene. Bull Faculty Pharm Cairo Univ 2014;52:109-14.

17. Rajesh BHV, Praveen KJ, Raveendra GB, Sri PLS, Praveen TK Rao PS. UV spectroscopic method for estimation of amlodipine besylate in tablets. Int J Pharm Chem Bio Sci 2014;4:69-73.

18. Samixa PR, Patel CN. Development and validation of spectrophotometric method for determination of aliskiren, amlodipine and hydrochlorothiazide in combined pharmaceutical dosage forms. Asian J Pharm Anal 2014;4:166-71.

19. Pawar PY, Mane BY, Sumit MA, Vipul VT. Simultaneous estimation of amlodipine besylate and atenolol in combined dosage form by Vierodt's method using U. V. spectroscopy. Der Pharma Chem 2013;5:97-102.

20. Laxmileena DP, Sachin VG, Deepali DJ, Yogita AK, Sampada DD, Pramod LI. Development and validation of UVspectrophotometric methods for simultaneous estimation of amlodipine besylate and clopidogrel bisulfate in bulk and tablet dosage form. Der Pharma Chem 2013;5:282-7.

21. Mahmoud RS, Parviz A, Maryam D. Simultaneous quantitative determination of amlodipine and atorvastatin in tablets using artificial neural networks. Math Com Modell 2013;58:1588-94.

22. Varsha RG, Baheti KG, Indraksha S, Dehghan MH. Estimation of amlodipine besylate, valsartan and hydrochlorothiazide in bulk mixture and tablet by UV spectrophotometry. Indian J Pharm Sci 2012;74:18-23.

23. Kondawar MS, Kamble KG, Raut KS, Maharshi KH. UV Spectrophotometric estimation of amlodipine besylate and telmisartan in bulk drug and dosage form by multi wavelength analysis. Int J Chem Tech Res 2011;3:1274-8.

24. Smita TK, Swapnil DJ, Neela MB, Manish SB. Development and validation of derivative spectrophotometric method for estimation of atorvastatin calcium and amlodipine besylate in tablet dosage form. Int J Pharm Pharm Sci 2011;3 Suppl 4:195-7.

25. Pandurang ND, Sunita RB. Simultaneous UV spectrophotometric methods for estimation of amlodipine besilate and olmesartan medoxomil in tablet dosage form. J Chem Pharm Res 2011;32:650-6.

26. Shyni B, Molly M, Senthilkumar KL. Spectrophotometric method of estimation of amlodipine besylate using hydrotropic solubilization. J Appl Pharm Sci 2011;1:177-80.

27. Gayathri S, Devi TSR, Gunasekaran S. Qualitative and quantitative analysis on some cardiovascular drugs. Asian J Chem 2010;22:5824-34

28. Kardile DP, Kalyane NV, Thakkar TH, Patel MR, Moradiya RK. Simultaneous estimation of amlodipine besylate and olmesartan medoxomil drug formulations by HPLC and UVspectrophotometric methods. J Pharm Sci Res 2010;2:599-614.

29. Bilal Y, Selcuk K. UV and first derivative spectrophotometric methods for the estimation of atorvastatin in pharmaceutical preparations. J Adv Pharma Res 2018;2:89-94.

30. Sobhy MAA, Lobna MAA, Maha AMM. Spectrophotometric determination of atorvastatin calcium and rosuvastatin calcium in bulk and dosage form using p-dimethylaminobenzaldehyde. J Appl Pharm 2017;9:233.

31. Alshabrawy A, Ahmed M, Nageh A. Sensitive spectrophotometric determination of atorvastatin in pharmaceutical formulation by ion pair complexation with pararosaniline hydrochloride. J Adv Pharma Res 2017;1:193-200.

32. Ramadan AA, Hasna M, Jenan S. Determination of atorvastatin calcium in pure and its pharmaceutical formulations using iodine in acetonitrile by uv-visible spectrophotometric method. Int J Pharm Pharm Sci 2015;7:427-33.

33. Jadhav NR, Ramesh SK, Sameer JN. Dual wavelength spectrophotometric method for simultaneous estimation of 
atorvastatin calcium and felodipine from tablet dosage form. Adv Chem 2014;6. http://dx.doi.org/10.1155/2014/131974

34. Suresh JNK, Babu CN, Dhanalakshmi T, Florence $K$, Ramanjaneyulu MS, Sambasivanaik N. Development and validation of spectrophotometric method for estimation of atorvastatin calcium bulk and pharmaceutical formulations. World J Pharma Pharm Sci 2014;3:1305-13.

35. Safila N. Simple uv spectrophotometric assay of atorvastatin API formulation and their comparative study. Global J Med Res: B Pharm Drug Discovery Toxi Med 2014;14:34-8.

36. Kailash PP, Bhandari A. Spectroscopic method for estimation of atorvastatin calcium in tablet dosage form. Indo Global J Pharma Sci 2011;1:294-9.

37. Swapnil DJ, Manish SB, Shivaji LT, Sachin AP. Spectrophotometric methods for estimation of atorvastatin calcium form tablet dosage forms. Int J Pharm Tech Res 2010;2:1948-53.

38. Sandeep SS, Atul AS, Ravindra AF, Sanjay JS. Application of UVspectrophotometry and RP-HPLC for simultaneous determination of atorvastatin calcium and ezetimibe in pharmaceutical dosage form. Eurasian J Anal Chem 2006;1:31-41.

39. Dhiraj K, Susanta KP, Sudhir KS. Development of stability indicating RP-HPLC method for simultaneous estimation of amlodipine and olmesartan in pure and pharmaceutical dosage form. Int J Pharm Sci Drug Res 2018;10:379-85.

40. Bhagyalaxmi C, Sahoo SK, Kavitha D, Nagamani M, Lagnajit M. Development and validation of new analytical RPHPLC method for the estimation of amlodipine and perindopril in tablet dosage form. Int J Pharma Res Health Sci 2018;6:2433-36.

41. Vidhi AM. RP-HPLC method development and validation for simultaneous estimation of irbesartan, amlodipine besylate and hydrochlorothiazide in tablet. World J Pharm Res 2018;7:690-701.

42. Abhi K, Manju M. Development and validation of RP-HPLC and UV-spectrophotometric methods for rapid simultaneous estimation of amlodipine and benazepril in pure and fixed dose combination. Arabian J Chem 2017;10:S3021-8.

43. Ariadne MB, Jerusa SG, Marcello GT. Development and validation of a chromatography method using tandem $\mathrm{UV} /$ charged aerosol detector for simultaneous determination of amlodipine besylate and olmesartan medoxomil: application to drug-excipient compatibility study. J Anal Methods Chem 2017;Vol 2017:8. https://doi.org/10.1155/2017/4878316

44. Osman RAM, Elbashir AA. Development and validation of stability indicating HPLC method for the simultaneous analysis of amlodipine, hydrochlorothiazide and valsartan in pharmaceutical formulation, J Anal Pharm Res 2017;6:00188.

45. Rasha AS, Tarek SB, Fawzy AEY, Sohila ME. Validated stabilityindicating HPLC-DAD method of analysis for the antihypertensive triple mixture of amlodipine besylate, valsartan and hydrochlorothiazide in their tablets. Arabian J Chem 2017;10:S1381-94.

46. Gunasekar M. Simultaneous determination and estimation of amlodipine and perindopril in raw and tablet formulation by stability indicating RP-HPLC method. IOSR J Pharma Biol Sci 2016;11:24-9.

47. Chamarthi RPK, Mohan GVK. Development and validation of amlodipine impurities in amlodipine tablets using design space computer modeling. Am J Anal Chem 2016;7:918-26.

48. Hassan SA, Elzanfaly ES, El-Zeany SB, Salem MY. Development and validation of HPLC and CE methods for simultaneous determination of amlodipine and atorvastatin in the presence of their acidic degradation products in tablets. Acta Pharm 2016;66:479-90.

49. Mounika P, Rani PJ, Pranathi G, Haque MA, Sireesha D, Harshini $\mathrm{S}$, et al. Development and validation of RP-HPLC method for the simultaneous estimation of amlodipine and metoprolol in bulk and pharmaceutical dosage form. Indo Am J Pharm Res 2015;5:3254-60.

50. Hafez HM, Elshanawany AA, Abdelaziz LM, Mohram MS. Development of a stability-indicating HPLC method for simultaneous determination of amlodipine besylate and atorvastatin calcium in tablets. Austin J Anal Pharm Chem 2014;1:11.
51. Manish S, Charmy K, Omkar S, Priti M. Concurrent estimation of amlodipine besylate, hydrochlorothiazide and valsartan by RP. HPLC, HPTLC and UV-spectrophotometry. J Chromatogr Sci 2014;52:27-35

52. Bharti AR, Deshmane SV, Biyani KR. Stability indicating RPHPLC method for development and validation for simultaneous estimation of amlodipine and hydrochlorothiazide in pharmaceutical dosage form. Int J Curr Pharm Res 2014;6:16-9.

53. Anandkumar RT, Gurupadayya BM, Soni N. Simultaneous estimation of hydrochlorothiazide, amlodipine, and losartan in tablet dosage form by RP-HPLC. Int J Chem Anal Sci 2013;4:33-8.

54. Samya MEG, Abdelmageed OH, Omar MA, Deryea SM, Abdel Megied AM. Development and validation of HPLC method for simultaneous determination of amlodipine, valsartan hydrochlorothiazide in dosage form and spiked human plasma. Am J Anal Chem 2012;3:422-30.

55. Karunakar N, Puranik SB, Kumar GVS, Masood MD, Sridhar KA. Development and validation of RP-HPLC method for simultaneous estimation of amlodipine and indapamide in bulk and tablet dosage form. Asian J Biomed Pharm Sci 2012;2:55-9.

56. Kayal SD, Khan FA, Tated AG, Bakal RL, Chandewar AV. Method development and validation for the simultaneous determination of amlodipine besylate and telmisartan in tablet dosage form by RP-HPLC. Int J Pharm Res Dev 2011;3:144-53.

57. Pournima SP, More HN, Pishwikar SA. RPHPLC method for simultaneous estimation of amlodipine besylate and olmesartan medoxomil from tablet. Int J Pharm Pharm Sci 2011;3 Suppl 3:146-9.

58. Hassan AA, Alnami AM, Arishi MAA, Alameer RK, Bratty MA, Rehman ZU, et al. A fast and validated reversed-phase HPLC method for simultaneous determination of simvastatin, atorvastatin, telmisartan and irbesartan in bulk drugs and tablet formulations. Sci Pharm 2018;86:1.

59. Rao S, Balaswami B, Ramana PV, Sanjeeva P, Srenivasulareddy G. New stability-indicating RP-HPLC-PDA method for simultaneous estimation of triplicate mixture of ramipril, atorvastatin and clopidogrel in tablet dosage form. Int J Appl Pharm 2018;10:90-6.

60. Azmi SNH, Al-Mamari AK, Al-Hosni BS, Al-Fazari MR. High performance liquid chromatographic-UV method for determination of atorvastatin calcium in pharmaceutical formulations. J New Dev Chem 2017;1:38-50.

61. Yusuf SM, Samparna S, Yallareddy K, Pavani B, Sivakala T. Analytical method development and validation of atorvastatin and clopidogrel in tablet dosage form by RP-HPLC. Eur J Pharma Med Res 2017;4:553-8.

62. Jaiprakash NS, Mohammed A, Zahid Z, Ahmed RZ, Dehghan MHG, Gonjari I. Development and validation of RP-HPLC method for determination of atorvastatin calcium and nicotinic acid in combined tablet dosage form. J Saudi Chem Soc 2016;20:S328-33.

63. Rudwan EH, Mohammed ABWE, Saeed AEM. A new RP-HPLC method for quantitative analysis of atorvastatin calcium in bulk and pharmaceutical dosage form by using design of experiment technique optimization. Int Res J Pure Appl Chem 2016;13:10.

64. Patil PM, Bobade AS. Development and validation of stability indicating RP-HPLC for determination of atorvastatin calcium and ezetimibe in bulk and pharmaceutical dosage forms. Int J Pharm Pharm Sci 2016;8:38-42.

65. Khaleel N, Rahaman SA. Validated stability indicating RP-HPLC method for simultaneous determination of atorvastatin, fenofibrate and folic acid in bulk and pharmaceutical dosage form. Der Pharm Lett 2016;8:13-32.

66. Patil PM, Bobade AS. Development and validation of stability indicating RP-HPLC for determination of atorvastatin calcium and ezetimibe in bulk and pharmaceutical dosage forms. Int J Pharm Pharm Sci 2016;8:38-42.

67. Rudwan EH, Hussien ABWEM, Saeed AEM. Development and validation of stability indicating high performance liquid chromatography method for determination of atorvastatin calcium in the presence of its degradation products. Der Pharma Sin 2015;6:19-27.

68. Octavian C, Spiridon AM, Belu I, Ftiolics AT, Neamuu J. Development and validation of an HPLC method for simultaneous quantification of clopidogrel bisulfate, its 
carboxylic acid metabolite, and atorvastatin in human plasma: application to a pharmacokinetic study. J Anal Methods Chem 2015;12. http://dx.doi.org/10.1155/2015/892470

69. Swamy GK, Rao JVLNS, Kumar JMR. New stability indicating validated RP-HPLC method for simultaneous estimation of irbesartan and atorvastatin in combined tablet dosage forms. Am J Pharm Tech Res 2015;5:380-9.

70. Simionato LD, Ferello L, Stamer SG, Repetto MF, Zubata PD, Segall AI. A validated reversed-phase HPLC method for the determination of atorvastatin calcium in tablets. Austin Chromatogr 2014;1:4.

71. Mallesh K, Sobahi TR, Helw AME, Abdelaal MY. Development and validation of a RP-HPLC method for assay of atorvastatin and its application in dissolution studies on thermosensitive hydrogelbased nanocrystals. Trop J Pharm Res 2014;13:1681-7.

72. Ramesh D, Habibuddin M, Dash RN, Humaira T. Simultaneous determination of atorvastatin calcium and losartan potassium in bulk and combined dosage forms by validated RP-HPLC with UV detection. Am J Pharm Tech Res 2013;31:675-85.

73. Bhinge SD, Malipatil SM, Jondhale A, Hirave R, Savali AS. A new approach to the RP-HPLC method for simultaneous estimation of atorvastatin calcium and fenofibrate in pharmaceutical dosage forms. E J Chem 2012;9:1223-9.

74. Ganesh M, Hemalatha P, Sakthimanigandan K, Mei PM, Lee SG. Simultaneous estimation of atorvastatin and ezetimibe in combined formulation by RP-HPLC. Asian J Chem 2012;24:1867-71.

75. Kumar P, Ghosh A, Chaudhary M. Stability indicating method development for simultaneous estimation of ezetimibe and atorvastatin in pharmaceutical formulations by RP-HPLC. Pharm Anal Acta 2012;3:164.

76. Charde MS, Gupta A, Chakole RD. Determination of atorvastatin calcium in pharmaceutical formulations by reverse phase-high performance liquid chromatography. Int J Adv Pharm Anal 2011;1:48-53.

77. Rupali H, Bendagude R, Kondawar M. RP-HPLC method for simultaneous estimation of atorvastatin calcium and fenofibrate in tablet dosage forms. J Pharma Res 2010;3:2400-1.

78. Mustafa G, Azeem A, Ahmad FJ, Khan ZI, Shakeel F, Talegaonkar S. Stability-indicating RP-HPLC method for analysis of atorvastatin in bulk drug, marketed tablet and nano emulsion formulation. J Chil Chem Soc 2010;55:184-8.

79. Jain N, Raghuwanshi R, Jain D. Development and validation of RP-HPLC method for simultaneous estimation of atorvastatin calcium and fenofibrate in tablet dosage forms. Indian J Pharm Sci 2008;70:263-5.

80. Seshachalam U, Kothapally CB. HPLC analysis for simultaneous determination of atorvastatin and ezetimibe in pharmaceutical formulations. J Liq Chromatogr Relat Tech 2008;31:714-21.

81. Shah DA, Bhatt KK, Mehta RS, Shankar MB, Baldania SL, Gandhi TR. Development and validation of a RP-HPLC method for determination of atorvastatin calcium and aspirin in a capsule dosage form. Indian J Pharm Sci 2007;69:546-9.

82. Stanisz B, Lukasz K. Validation of HPLC method for determination of atorvastatin in tablets and for monitoring stability in solid phase. Acta Poloniae Pharm Drug Res 2006;63:471-6.

83. Sidika E, Aktas ES, Ersoy L, Ficicioglu S. An HPLC method for the determination of atorvastatin and its impurities in bulk drug and tablets. J Pharm Biomed Anal 2003;33:1017-23.

84. Bharti T, Richa S. Development of short and robust analytical method on UPLC-MS for quantitative estimation of different API's in their formulated products-a green analytical chemistry approach. Eur J Biomed Pharm Sci 2017;4:405-17.

85. Balakrishnan A, Vijay AR, Senthilkumar N, Gangadevi N. Analytical method development and validation of amlodipinean antihypertensive and chlorthalidone-a thiazide diuretic by RP-UPLC method. Int J Chem Pharm Sci 2016;7:12-7.

86. Hanan AM, Nesrin KR, Sherine SD, Azza AM. Development and validation of UPLC methods for simultaneous determination of selected antihypertensive drugs in their dosage forms. Int J Adv Sci Eng Tech 2015;3:45-50.

87. Patel KN, Patel NB, Sevak MR, Desai HT. Development and validation of RP-UPLC method for simultaneous estimation of amlodipine and indapamide in their combined tablet dosage form. J Pharm Sci Bio Sci Res 2015;5:101-9.
88. Waghmare AN, Muddukrishna BS, Vasantharaju SG. Analytical method development and validation of simultaneous estimation of amlodipine and atorvastatin by RP-UPLC. Mintage J Pharm Med Sci 2014;3 Suppl 2:22-5.

89. Mallikarjuna S, Ramalingam P, Sriram P, Garima J, Srinivas SK. Development and validation of stability indicating RP-UPLC method for simultaneous estimation of amlodipine besylate and atorvastatin calcium in pharmaceutical dosage forms. J Chromatogr Sep Tech 2013;4:187.

90. Santaji N, Vangala RR, Rao DD, Rao IK. Rapid simultaneous determination of telmisartan, amlodipine besylate and hydrochlorothiazide in a combined poly pill dosage form by stability-indicating ultra-performance liquid chromatography. Sci Pharm 2011;79:69-84.

91. Lakshmi NYS, Barhate VD. Development and validation of stability indicating UPLC method for the simultaneous determination of beta-blockers and diuretic drugs in pharmaceutical dosage forms. J Chem Metrol 2010;4:1-20.

92. Lakshmi KS, Seetharaman R. Design and study of reverse phase ultra-high performance liquid chromatographic method for simultaneous estimation of two antidiabetic drugs with an antihyperlipemic drug using statistical approach. Int J Pharm Pharm Sci 2014;6:257-62.

93. Darwish MK, Manal MF, Zaazaa HE, Razeq SAA, Zeinab AN. Formulation, optimization and simultaneous determination of atorvastatin calcium and losartan potassium in pure and bilayer tablets, J Global Trends Pharm Sci 2014;5:1756-68.

94. Goel A, Sanjula B, Jasjeet KS, Kona SS, Ravi SG, Gupta A, et al. Development and validation of stability-indicating assay method by UPLC for a fixed dose combination of atorvastatin and ezetimibe. J Chromatogr Sci 2013;51:222-8.

95. Kakumani KK, Rao CK, Lakshmi MV, Mukkanti K. A validated stability indicating RP-UPLC method for atrovastain calcium. Am J Anal Chem 2012;3:392-9.

96. Kaila HO, Ambasana MA, Shah AK. A simple and rapid ultraperformance liquid chromatographic assay method for the simultaneous determination of aspirin, clopidogrel bisulphate and atorvastatin calcium in capsule dosage form. Int J Chem Tech Res 2011;3:459-65.

97. Shetty SK, Surendranath KV, Radhakrishnanand P, Borkar RM, Devrukhakar PS, Johnson J, et al. Stress degradation behavior of a polypill and development of stability indicating UHPLC method for the simultaneous estimation of aspirin, atorvastatin, ramipril and metoprolol succinate. Am J Anal Chem 2011;2:401-10.

98. Seshadri RK, Desai MM, Raghavaraju TV, Krishnan D, Rao DV, Chakravarthy IE. Simultaneous quantitative determination of metoprolol, atorvastatin and ramipril in capsules by a validated stability indicating RP-UPLC method. Sci Pharm 2010;78:821-34.

99. Abdul AR, Hussen AA, Mohammad M. TLC simultaneous determination of amlodipine, atorvastatin, rosuvastatin and valsartan in pure form and in tablets using phenyl-modified aleppo bentonite. Int J Pharm Pharma Sci 2014;6:180-8.

100. Shirkhedkar A, Surana S. Simultaneous densitometric TLC analysis of atorvastatin calcium and fenofibrate in the bulk drug and in pharmaceutical formulations. J Plan Chromatogr Mod TLC 2009;22:355-8.

101. Nikalje AG, Choudhari VP. Validated TLC method for simultaneous quantitation of atorvastatin, ezetimibe, and fenofibrate in bulk drug and formulations. Acta Chromatogra 2011;23:267-80.

102. Logoyda L, Korobko D, Saprun S. Development of methods for identification of calcium channel blockers in medicines. Int J Res Ayurved Pharm 2016;7:88-91.

103. Sonia K, Manikandan K, Hamunyare N, Peddamadi BS, Lakshmi KS. Method development and validation of simultaneous estimation for amlodipine besylate and olmesartan medoxomil by HPTLC method. Int J Res Pharm Sci 2018;9:201-5.

104. Rao NM, Sankar DG. Development and validation of HPTLC method for the simultaneous estimation of amlodipine besylate and atorvastatin calcium in combined dosage form. Eurasian J Anal Chem 2016;11:155-68.

105. Marolia BP, Bodiwala KB, Shah SA, Prajapati PB, Satani BH, Desai SA. Development and validation of HPTLC method for simultaneous estimation of amlodipine besylate, 
hydrochlorothiazide and telmisartan in their combined tablet dosage form. Pharm Methods 2016;7:48-53.

106. Shah DA, Patel DV, Mehta FA, Chhalotiya UK, Bhatt KK. Highperformance thin-layer chromatography method for estimatingthe stability of a combination of irbesartan and amlodipine besylate. J Taibah Univ Sci 2015;9:177-86.

107. Sindhav JR, Chhalotiya UK, Shah DA, Mehta FA, Bhatt KK. Stabilityindicating HPTLC method for simultaneous quantification of moxonidine and amlodipine besylate in their combined pharmaceutical dosage form. Austin Chromatogr 2015;2:1031, 7.

108. Jain PS, Patel MK, Surana SJ. Development and validation of HPTLC method for simultaneous determination of amlodipine besylate and metoprolol succinate in bulk and tablets. Indian J Pharm Sci 2012;74:152-6.

109. Kothapalli LP, Panchaware MS, Nanda RK, Thomas AB. Stabilityindicating HPTLC method for simultaneous determination of lisinopril anhydrate and s-amlodipine besylate in pharmaceutical dosage form. Asian J Res Chem 2012;5:1061-6.

110. Deshmukh TB, Deo SS. Development and validation of novel HPTLC method for the simultaneous estimation of atorvastatin calcium and telmisartan in tablet dosage form. Int J Pharm Chem Biol Sci 2018;8:82-90.

111. Misari PK, Ezhava SB. Development and validation of HPTLC method for simultaneous estimation of atorvastatin calcium and vitamin $\mathrm{d}_{3}$ in pharmaceutical dosage form. World J Pharm Sci 2014:2:1511-9.

112. Kolsure AK, Chavan BB, Chabukswar AR, Kuchekar BS. Development and validation of a HPTLC method for simultaneous estimation of atorvastatin calcium and losartan potassium in combined dosage form. J Med Pharm Innov 2014;1:21-5.

113. Kaliappan I, Kumar PSS. Development and validation of stability indicating HPTLC and HPLC methods for simultaneous determination of telmisartan and atorvastatin in their formulations. J Chem 2013. http://dx.doi.org/10.1155/ 2013/725385.

114. Ginoya CG, Thakkar DV. Development and validation of HPTLC method for simultaneous determination of metoprolol succinate and atorvastatin calcium in a pharmaceutical dosage form. Int Res J Pharma 2013;4:102-7.

115. Wankhede SB, Dixit NR, Chitlange SS. Stability indicating HPTLC method for quantitative determination of atorvastatin calcium and metoprolol succinate in capsules. Der Pharmacia Lett 2011;3:1-7.

116. Mohamed MH, Maha S, Haya AJ. Development of capillary electrophoresis technique for simultaneous measurement of amlodipine and atorvastatin from their combination drug formulations. J Liq Chromatogr Relat Technol 2009;32:2923-42.

117. Alshehri MM. A validated capillary electrophoresis method for simultaneous determination of ezetimibe and atorvastatin in pharmaceutical formulations. Saudi Pharm J 2012;20:143-8

118. Eleonora M, Teodora B, Gabriel H, Valentin I, Anca C. Simultaneous determination of amlodipine and atorvastatin by capillary electrophoresis from fixed pharmaceutical formulations. Farmacia 2016;64:398-402.

119. Said AH, Eman SE, Maissa YS, Badr AEZ. Development and validation of HPLC and CE methods for simultaneous determination of amlodipine and atorvastatin in the presence of their acidic degradation products in tablets. Acta Pharm 2016;66:479-90.

120. Modroiu A, Hancu G, Vlad RA, Stacescu S, Soare R, Kelemen H. Simultaneous determination of amlodipine and telmisartan from pharmaceutical products by way of capillary electrophoresis. Curr Issues Pharm Med Sci 2016;29:42-5.

121. Mahesh A, Adbullah B, Hussain MB. Capillary electrophoresis method development for simultaneous determination of atorvastatin and ezetimibe from solid dosage form. J Young Pharm 2017;9:122-5.

122. Blanka SS, Gabriel H, Istvan SS, Bela K, Hajnal K. Simultaneous determination of atorvastatin and ezetimibe from combined pharmaceutical products by micellar electrokinetic capillary chromatography. Braz J Pharm Sci 2017;53:e16122.

123. Wanga L, Liua W, Zhanga Z, Tiana Y. Validated LC-MS/MS method for the determination of amlodipine enantiomers in rat plasma and its application to a stereo selective pharmacokinetic study. J Pharm Biomed Anal 2018;158:74-81.

124. Haque AM, Priya SDK, Mohanty D, Bakshi V, Boggula N. Analytical method development and validation of amlodipine in human plasma using liquid chromatography-mass spectrometry/mass spectrometry. Asian J Pharm Clin Res 2018;11:393-7.

125. Shah JV, Parekh JM, Shah PA, Shaha PV, Sanyal M, Shrivastav PS. Application of an LC-MS/MS method for the analysis of amlodipine, valsartan and hydrochlorothiazide in polypill for a bioequivalence study. J Pharm Anal 2017;7:309-16.

126. Hossein D, Hamidi M. Method validation of amlodipine and atorvastatin by liquid chromatography-mass spectrometry (LCMS) method in human plasma. Cogent Med 2016;3:1129790.

127. Alvi SN, Hussein RF, Dgither SA, Hammami MM. Quantitation of amlodipine in human plasma by LCMS/MS assay. Int J Pharm Pharm Sci 2016;8:268-72.

128. Jangala H, Vats $P$, Khuroo AH, Monif T. Development and validation of a LC-MS/MS method for the simultaneous estimation of amlodipine and valsartan in human plasma: application to a bioequivalence study. Sci Pharm 2014;82:585-600.

129. Shankar GG, Deme P, Kuncha M, Sistla R. Simultaneous determination of amlodipine, valsartan and hydrochlorothiazide by LC-ESI-MS/MS and its application to pharmacokinetics in rats. J Pharm Anal 2014;4:399-406.

130. Chan ML, Wei CM, Bu FL, Chen R, Wang XL, Li R, et al. Determination of amlodipine in human plasma by LC-MS/MS and its bioequivalence study in healthy chinese subjects. Pharmacol Pharma 2013;4:191-200.

131. Sakac MC, Vujic Z, Vujcic Z, Markovic B, Vasiljevic D. LC-MS/MS method for quantification of atorvastatin, ohydroxyatorvastatin, p-hydroxyatorvastatin, and atorvastatin lactone in rat plasma. Acta Chromatogr 2016;28:281-98.

132. Jiang W, Luzum JA, Phelpsa MA, Kitzmiller JP. Liquid chromatography-tandem mass spectrometry assay for the simultaneous quantification of simvastatin, lovastatin, atorvastatin, and their major metabolites in human plasma. J Chromatogr B 2015;983-984:18-25.

133. Partani P, Verma SM, Gurule S, Khuroo A, Monif T. Simultaneous quantitation of atorvastatin and its two active metabolites in human plasma by liquid chromatography/(-) electrospray tandem mass spectrometry.J Pharm Anal 2014;4:26-36.

134. Ramzia IEB, Elkady EF, Sherif ZAE, Kadry AM. LC-MS-MS simultaneous determination of atorvastatin and ezetimibe in human plasma. J Chromatogr Sci 2014;52:773-80.

135. Gajula R, Pilli NR, Ravi VB, Maddela R, Inamadugu JK, Polagani SR, Busa S. Simultaneous determination of atorvastatin and aspirin in human plasma by LC-MS/MS: its pharmacokinetic application. Sci Pharm 2012;80:923-40.

136. Ashutosh JJ, Dasandi B, Rathnam S, Mehta AA. Liquid chromatographic-MS/MS determination of atorvastatin and metabolites in human plasma. Eurasian J Anal Chem 2010;5:46-52.

137. Kalaiyarasi D, Jaganathan KS, Krishna MV. Bioanalytical method validation for perindopril and amlodipine in human plasma using UPLC/ESI-MS/MS. World J Pharm Res 2018;7:1567-80.

138. Ahmed M, Alshabrawy A, Nageh A. UPLC-MS/MS method for kinetic studies and simultaneous determination of amlodipine and atorvastatin in bulk, and their combined dosage form. Anal Chem Ind J 2016;16:102.

139. Walid ME, Elkady EF, Zaher AAE, Bagary RIE, Patonay G. Simultaneous determination of aliskiren hemifumarate, amlodipine besylate and hydrochlorothiazide in spiked human plasma using UPLC-MS/MS. J Chromatogr Sci 2015;53:1178-84.

140. Xia B, Li Y, Zhang Y, Xue M, Li X, Xu P, et al. UHPLC-MS/MS method for determination of atorvastatin calcium inhuman plasma: application to a pharmacokinetic study based on healthy volunteers with specific genotype. J Pharm Biomed Anal 2018;160:428-35.

141. Liyun C, Zhijie Z, Xipei W, Lan T, Liping M, Guodong H, et al. Simultaneous determination of atorvastatin and its metabolites in human plasma by UPLC-MS/MS. Anal Methods 2017;9:1038-45.

142. Lucie N, Hana V, Dalibor S, Petr S, Dagmar S, Milan B, et al. Ultrahigh performance liquid chromatography tandem mass spectrometric detection in clinical analysis of simvastatin and atorvastatin. J Chromatogr B 2009;877:2093-103. 